\title{
Recent and future developments in earthquake ground motion estimation
}

\author{
John Douglas ${ }^{\mathrm{a}, *}$, Benjamin Edwards ${ }^{\mathrm{b}}$ \\ ${ }^{a}$ Department of Civil and Environmental Engineering; University of Strathclyde; \\ James Weir Building; 75 Montrose Street; Glasgow; G1 1XJ; United Kingdom \\ ${ }^{b}$ Department of Earth, Ocean and Ecological Sciences; School of Environmental Sciences; \\ University of Liverpool; Jane Herdman Building; Liverpool; L69 3GP; United Kingdom
}

\begin{abstract}
Seismic hazard analyses (SHA) are routinely carried out around the world to understand the hazard, and consequently the risk, posed by earthquake activity. Whether single scenario, deterministic analyses, or state-of-the art probabilistic approaches, considering all possible events, a founding pillar of SHA is the estimation of the ground-shaking field from potential future earthquakes. Early models accounted for simple observations, such that ground shaking from larger earthquakes is stronger and that ground motion tends to attenuate rapidly away from the earthquake source. The first ground motion prediction equations (GMPEs) were, therefore, developed with as few as two principal predictor variables: magnitude and distance.

Despite the significant growth of computer power over the last few decades, and with it the possibility to compute kinematic or dynamic rupture models coupled with simulations of $3 \mathrm{D}$ wave propagation, the simple parametric GMPE has remained the tool of choice for hazard analysts. There are numerous reasons for this. First and foremost GMPEs are robust and reliable
\end{abstract}

\footnotetext{
${ }^{*}$ Corresponding author

Email addresses: john.douglas@strath.ac.uk (John Douglas), ben.edwards@liverpool.ac.uk (Benjamin Edwards)
} 
within the model space considered during their derivation, and many can be extrapolated to a degree beyond this space with some confidence. With ever expanding datasets and improved metadata the models are becoming more and more useful: a range of predictor variables are now used, describing the source, path and site effects in detail. GMPEs are also relatively easy to implement and computationally inexpensive. Despite this, probabilistic hazard calculations using GMPEs and accounting for uncertainties can still take several days to run. Full simulation-based approaches, therefore, clearly lie outside the computation budget afforded to most projects.

As well as the ever expanding list of predictor variables, other recent developments have also significantly improved the predictive power of GMPEs. This has allowed them to maintain their advantage over more 'physical' simulation techniques. Possibly the biggest aspect of this is not related to the median ground-shaking field, but rather its variability (and correlation in space and with oscillator period). This is a major advantage of empirical as opposed to simulation approaches, which typically struggle to replicate the covariance of input variables and, consequently, the variance of the ground motion. In this article we summarize some of the recent advances in ground motion prediction equations, including their application in SHA. We begin with a summary of the current state-of-the-art, then introduce the main additional predictor variables now used. Region- and event-type (tectonic or induced) specific predictions and adjustments are then discussed. Additional topics include advances in estimating ground-motion variability (epistemic and aleatory) and expanding GMPEs to predict other intensity measures or waveform features. The article concludes with a discussion on the path forward in earthquake ground motion prediction.

Keywords: seismology, earthquake engineering, earthquake, induced 
seismicity, seismic hazard, ground-motion model

\section{Introduction}

2 Seismic hazard assessment for a given site is founded on two pillars: 3 firstly, a seismic-source model quantitatively describing all possible earth4 quakes in the vicinity (generally within about $300 \mathrm{~km}$ ) and, secondly, a 5 ground-motion model expressing the shaking that would happen at the site 6 given the occurrence of each of these earthquakes. This article focuses on the 7 second of these components; nevertheless, when considering ground-motion 8 models it is vital to bear in mind the descriptions of earthquakes contained 9 within the seismic-source model. These descriptions invariably consist of o the earthquake's geographical location (and depth), its magnitude and, in11 creasingly, its faulting mechanism and other characteristics (e.g. rupture 12 geometry).

13 The results of seismic hazard assessments are vital inputs to earthquake 14 engineering as they provide the motions that need to be resisted by structures and infrastructure constructed at the site. In the past most earthquake 16 engineering analyses were based on the response spectral representation of 17 shaking (e.g. Newmark and Hall, 1982; Chopra, 1995) or other pseudo18 static methods. Consequently only estimates of scalar intensity measures 19 (IMs), the principal ones being peak ground acceleration (PGA) and velocity 20 (PGV) and elastic response spectral accelerations (SA) at various structural 21 periods between 0 and commonly $2 \mathrm{~s}$, were required for engineering analysis. In the past decade or so, Incremental Dynamic Analysis (Vamvatsikos and Cornell, 2002) and other time-history-based approaches have become increasingly used. There is a growing need, therefore, for seismic hazard 
analysts to provide a time-history representation of earthquake shaking in addition to estimates of various IMs.

As stated by Douglas et al. (2015), although the characterization of earthquake shaking by a single number (an IM) is a great simplification, it makes seismic hazard assessment much more straightforward since the link between the seismic-source and ground-motion models can be expressed as a closed-form equation [ground motion prediction equations (GMPEs), also known as attenuation relation(ship)s] to estimate the probability of exceeding a given level of earthquake shaking. These probabilities are calculated through probabilistic seismic hazard assessment (PSHA) (Cornell, 1968; McGuire, 1976), which is the basis of most current seismic design maps, e.g. the National Annexes of Eurocode 8 (Comité Européen de Normalisation, 2005) and ASCE-7 (ASCE, 2013). Consequently it is still common to assess seismic hazard using PSHA through ground-motion models that return IMs. Then, based on this analysis and if needed, to obtain earthquake time-histories for the most important scenarios, generally defined using disaggregation (Bazzurro and Cornell, 1999), either through selection from a databank of natural accelerograms (NIST, 2011) or simulations of artificial records (Douglas and Aochi, 2008).

Because of the key role they still play in seismic hazard assessment, this review focuses on GMPEs derived empirically (i.e. from seismograms of real earthquakes). The purpose of this article is not to repeat the historical review of empirical ground motion estimation presented by Douglas (2003a) nor the overall scope of the review of all methods for ground-motion prediction by Douglas and Aochi (2008). Rather, this article seeks to review the great advances in ground-motion prediction over the past decade and to provide the reader with an overview of the principal topics of research. The 
article concludes with some recommendations for future developments.

Although much of the following discussion concerns topics that are relevant for all tectonic regimes (e.g. shallow active crustal, subduction and stable continental) the examples are mainly taken from studies related to ground motions in shallow active crustal environments. A review focused on other tectonic regimes may emphasize other issues (e.g. the importance of focal depth for subduction events and simulation-based ground-motion models for stable continental regions). The wealth of data from shallow active crustal areas means that epistemic uncertainties are probably lower than in other tectonic regimes (e.g. Douglas, 2010b, Compare Figures 2, 8 and 10). For instance, in some tectonic regimes (e.g. oceanic crust, deep Vrancea-type and the Himalaya) there are few strong-motion observations to constrain ground-motion models and consequently the epistemic uncertainty for these regions is much higher than for shallow active crustal areas.

\section{Summary of current state of practice}

It has now been more than fifty years since the first ground-motion model accounting for both magnitude and distance dependence was derived (Esteva and Rosenblueth, 1964). Models are currently published at the rate of more than one per month and, at the last count, the total number of empirical equations for the prediction of PGA was 400 with many more based on simulations (Douglas, 2016). The close match between the rate of increase in strong-motion recordings and the number of GMPEs is shown in Figure 1. The rapidly increasing number of GMPEs led Bommer et al. (2010) to recommend criteria for the selection of GMPEs to retain only those models for consideration that could be thought of as representing the state of the art. 


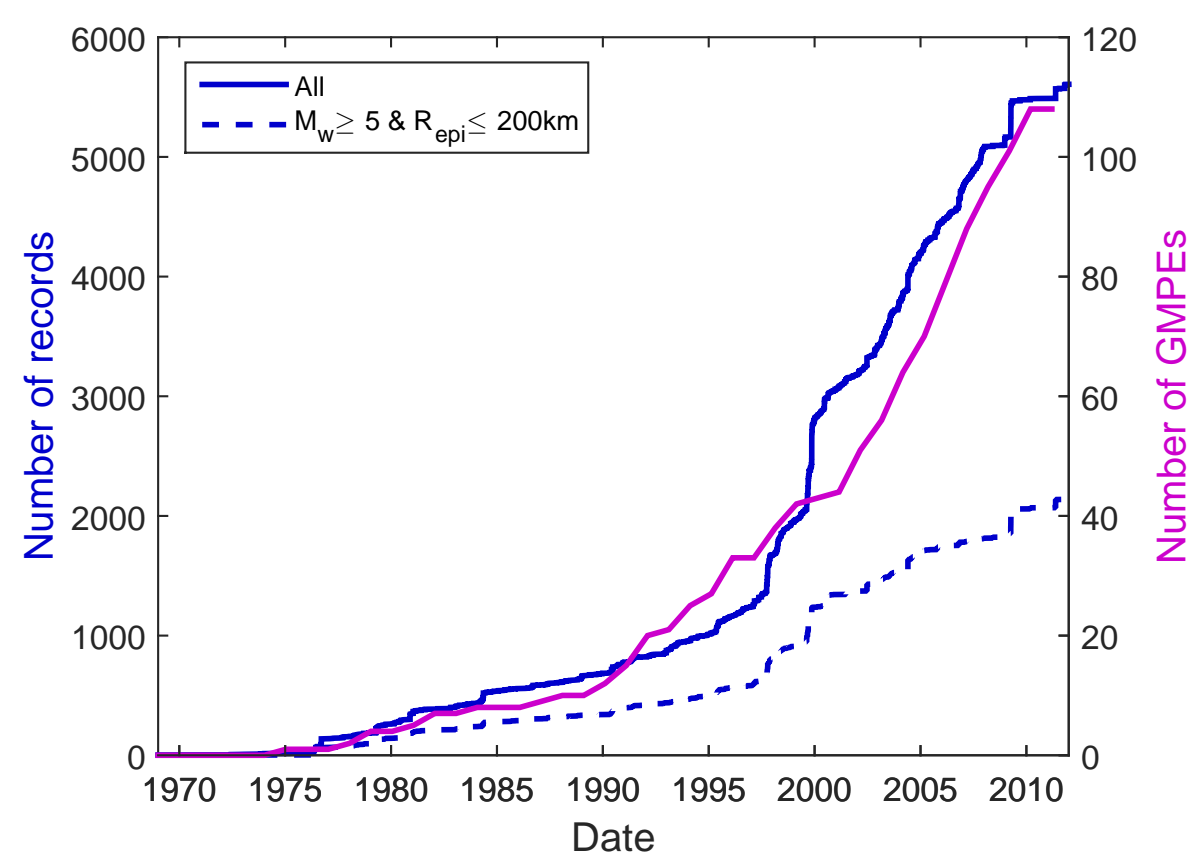

Figure 1: Available strong-motion records from RESORCE (Akkar et al., 2014b) (left-hand axis) and number of published GMPEs from Douglas (2016) (right-hand axis) against date for Europe and the Middle East (up to 2012).

77 They also suggest that these criteria could be used as a quality assurance 78 step to guide publication of new GMPEs.

79 A brief comparison between the first ground-motion model (Esteva and 80 Rosenblueth, 1964) and the recently-published GMPE of Abrahamson et al. 81 (2014) helps demonstrate the developments in this field. The GMPE of 82 Esteva and Rosenblueth (1964) was based on only 46 records and its three 83 coefficients were estimated via standard least-squares regression. In contrast 84 the model of Abrahamson et al. (2014) is based on over 15000 records from 85 more than 300 earthquakes and its roughly 40 coefficients were determined ${ }_{86}$ based on random-effects regression (Abrahamson and Youngs, 1992) or con- 


\footnotetext{
${ }^{1}$ The extension to shorter periods is aided by the observation (Douglas and Boore, 2011; Bommer et al., 2012) that SA is relatively unaffected by high-cut filtering.
} 
more careful consideration of how the models perform beyond their 'comfort zones', e.g.: for $\mathbf{M}<5, \mathbf{M}>7$ and $R<10 \mathrm{~km}$; and making the models easier to use and test within PSHA (see Section 4). In addition, there has been a growing interest in developing models for other IMs, e.g. peak ground displacement, Arias intensity and various duration measures (see Section 7).

\subsection{Current de facto standards}

As demonstrated by the review of Douglas (2003a) many different choices, in terms of dependent and independent variables, derivation technique and functional form, were made by GMPE developers until the 1990s. In the past couple of decades, however, there has been a general convergence to a set of de facto standards.

Most developers now present models for PGA, increasingly PGV, and pseudo-SA for $5 \%$ of critical damping based on the geometric mean of the values from two horizontal components, or the orientation-independent horizontal component (Boore et al., 2006). They often use records from public online databases (e.g. Akkar et al., 2014b; Chiou et al., 2008) that have been low-cut filtered with record-specific cut-offs that are then respected when considering the reliable frequency ranges of their models.

The size of an earthquake is invariably characterized in terms of moment magnitude (M), although this is sometimes estimated from other magnitudes, commonly local magnitude $\left(M_{L}\right)$ (e.g. Bindi et al., 2005; GoertzAllmann et al., 2011), duration magnitude $\left(M_{d}\right)$ (e.g. Bakun, 1984; Edwards and Douglas, 2014) or surface wave magnitude $\left(M_{s}\right)$ (e.g. Ambraseys and Free, 1997), through region-specific equations. Generally the earthquake is characterized into three faulting mechanisms (styles of faulting): normal, strike-slip and reverse. It is now common to consider nonlinear magnitude 
scaling (see Section 4.2).

The length of the travel path from source to site is generally measured either in terms of the distance to the surface projection of the rupture (the socalled Joyner-Boore distance, $r_{j b}$ ) (Joyner and Boore, 1981) or, accounting for the depth, the distance to the causative fault (the so called rupture distance, $\left.r_{\text {rup }}\right)$. For smaller earthquakes, where point sources can be assumed, these distance metrics become equal to epicentral $\left(r_{e p i}\right)$ and hypocentral $\left(r_{\text {hyp }}\right)$ distances, respectively. Some recent studies present models for both finite-fault $\left(r_{r u p}\right.$ or $\left.r_{j b}\right)$ and point-source $\left(r_{e p i}\right.$ or $\left.r_{h y p}\right)$ distance metrics so that the correct GMPE is available when used within PSHA for point sources (e.g. within area sources) (Bommer and Akkar, 2012) without having to perform conversions. It is also common to account for magnitude-dependent decay of IMs with distance (see Section 4.2).

Because boreholes were typically drilled to $30 \mathrm{~m}$ and because of its subsequent use within many projects and design codes, e.g. Eurocode 8, the timeaverage shear-wave velocity in the top $30 \mathrm{~m}\left(V_{s, 30}\right)$ is the common way that near-surface site conditions are characterized within recent GMPEs, either directly or, when insufficient information is available, through site classes. It is still relatively uncommon for GMPEs to account directly for potential nonlinear site amplification because this behavior is rare within observed strong ground motions. Within PSHA non-linear effects generally require a simulation-based site term to be adopted, often from a stand-alone study (Kamai et al., 2014; Seyhan and Stewart, 2014; Sandikkaya et al., 2013).

Finally it has become standard to use either random-effects (Abrahamson and Youngs, 1992) or one- or two-stage maximum-likelihood regression (Joyner and Boore, 1993) to estimate the free coefficients of the model. These techniques, applied to the same data, would lead to very similar 
results, although the latter may be more susceptible to trade-offs. Both techniques provide estimates of the between- and within-event components of ground-motion variability (see Section 5).

\section{Additional independent variables}

To obtain GMPEs that estimate more appropriate ground motions for a given earthquake, path and site, independent variables in addition to magnitude, faulting mechanism, source-to-site distance and a near-surface site class (or $V_{s, 30}$ ) have been tested and/or included within some recent models. These attempts are briefly discussed in this section.

\subsection{Source parameters}

All GMPEs include magnitude as the main source parameter. This is now routinely moment magnitude due to its robustness, the fact that it does not saturate, and because it is possible to estimate from historical and palaeological information. The latter consideration is important in linking GMPEs to earthquake catalogs, where the longer the available time-period the more reliable are recurrence relations, particularly at higher magnitudes. While magnitude is certainly an important factor for ground-motion amplitudes, there are other source parameters that can control the amplitude and frequency content of radiated seismic energy. The most influential of these is the earthquake stress drop. While the stress drop has a physical meaning, there are different definitions (e.g. static, dynamic or 'Brune'). When referred to in engineering seismology applications 'stress drop' or 'stress parameter' is effectively used to refer to the proportion of high-frequency energy (for a given magnitude) that is radiated from the source (Atkinson and Beresnev, 1997). 
Following on from observations of Somerville (2003), model developers of the NGA West 1 and 2 projects (Power et al., 2008; Bozorgnia et al., 2014) investigated the impact of depth to the top of the rupture plane $\left(Z_{T O R}\right)$ on ground motions. Some of them (e.g. Campbell and Bozorgnia, 2014) find that using $Z_{T O R}$ within the model leads to statistically better predictions with deep earthquakes generating higher ground motions than shallow events (all other things being equal), which could be explained by higher stress drops. Possible lower stress drops for aftershocks is behind the decision of some NGA West developers to exclude data from this type of event (e.g. Boore and Atkinson, 2008) whereas others (e.g. Chiou and Youngs, 2008) include terms to account for this difference. This effect appears to be small and could be related to the way that earthquakes are classified (Douglas and Halldórsson, 2010). Radiguet et al. (2009) present evidence that SAs from immature faults are statistically-significantly higher than those from mature faults, which again could be related to higher stress drops for earthquakes occurring on immature faults. The maturity of faults has yet to be included in a GMPE because the age of faults is not a readily-available parameter. The recent ground-motion model by Bora et al. (2015) includes an explicit term for the stress (drop) parameter $(\Delta \sigma)$ commonly used within stochastic models (e.g. Atkinson and Silva, 2000; Rietbrock et al., 2013), while Douglas et al. (2013) and Bommer et al. (2016) present unique GMPEs for a range of $\Delta \sigma$. This allows models to be readily employed in areas where the average stress drop is known but it puts the onus on the user to select an appropriate median $\Delta \sigma$ (and uncertainty about this value).

Directivity of earthquake ground motion fields is an emerging topic that has been addressed, for example, in the recent NGA West 2 project (Spudich et al., 2014). While often clear in large-magnitude earthquake simulations, 
this issue has seen relatively little focus in recent years. This is primarily due to the nature of PSHA, which combines all possible earthquake scenarios: rupture directivity effects, therefore, tend to be smoothed out. However, in understanding deterministic hazard, or for future analyses, where rupture directivity preference can be assigned, accounting for this effect may help to reduce epistemic uncertainty.

\subsection{Path parameters}

Path terms within GMPEs have grown more complex in terms of their functional form over the past decade with the realization that ground motions from small and large earthquakes do not decay at the same rate (see Section 4.2). In addition, because of the availability of ground-motion data (often from broadband instruments or high-sensitivity strong-motion sensors) at distances greater than $100 \mathrm{~km}$ (roughly the limit of analogue strongmotion recording) a number of GMPEs include terms to model anelastic attenuation, the rate of which is sometimes considered regionally-dependent (see Section 4). Cousins et al. (1999), for example, developed a GMPE for New Zealand that accounts for additional attenuation for travel paths through volcanic regions by including a term that is a function of the horizontal distance through such zones.

Nevertheless, commonly travel path is simply parameterized using sourceto-site distance. This means that the decay rate is the same for all locations irrespective of the crustal structure. Douglas et al. (2004, 2007) develop a technique based on simulations to calculate an equivalent hypocentral distance that captures the impact of crustal structure on ground-motion decay and, consequently, allows a ground-motion model to be branched into regionspecific models. This approach has yet to be applied for the derivation of a 
GMPE for use in practice.

A handful of GMPEs (generally for use in California) include terms to model the location of a site with respect to the hanging and foot walls of the causative fault (e.g. Campbell and Bozorgnia, 2014; Abrahamson et al., 2014 ), sometimes by using $R_{x}$ (the horizontal, strike-normal distance to the shallowest part of the surface projection of the fault). The terms to model this effect are often complex and hence rely on simulations to constrain their free parameters. For applications in areas without clearly-defined dipping faults such terms are often turned off when the model is used within PSHA.

\subsection{Site parameters}

As discussed in Section 2.1, most current GMPEs use $V_{s, 30}$ or site classes based on $V_{s, 30}$ to characterize the near-surface conditions at a site. In an attempt to account for the effect of deeper structure on ground motions, some recent GMPEs for California often use, in addition to $V_{s, 30}$, either the depth to the $1 \mathrm{~km} / \mathrm{s}$ velocity horizon $\left(Z_{1.0}\right)$ (e.g. Chiou and Youngs, 2014) or the depth to the $2.5 \mathrm{~km} / \mathrm{s}$ horizon $\left(Z_{2.5}\right)$ (e.g. Campbell and Bozorgnia, 2014). $Z_{1.0}$ and $Z_{2.5}$ are often strongly correlated but weakly correlated with $V_{s, 30}$ and hence their use alongside $V_{s, 30}$ adds discriminatory power to a GMPE. For many parts of the world estimates of $Z_{1.0}$ and, particularly, $Z_{2.5}$ are, however, difficult to obtain because they require knowing the shear-wave velocity down to hundreds or thousands of meters. Consequently, empirical relationships to estimate these parameters from $V_{s, 30}$ have been proposed (Boore et al., 2011) to center the predictions at an average $Z_{1.0}$ or $Z_{2.5}$.

PSHA is often conducted for a rock site with $V_{s, 30}$ equal or larger than $760 \mathrm{~m} / \mathrm{s}$ [the NEHRP B/C boundary (National Earthquake Hazard Reduction Program, 1994)] (see Section 4.4). At high $V_{s, 30}$ the site amplification 
modeled in the GMPE will be low and any nonlinearity in modeled response weak. One of the largest changes in PSHA for such sites in the past decade has been the appreciation that site amplification related to shear-wave velocity is not the whole story but that high-frequency attenuation, generally modeled by $\kappa$ (Anderson and Hough, 1984), also needs to be considered. The effect of an average $\kappa$ is implicitly captured within empirical GMPEs through the data that are used. The average $\kappa$ implied by the shape of the short-period spectra of GMPEs evaluated for high $V_{s, 30}$ is, however, often much higher than the $\kappa$ measured at rock sites. Consequently, as discussed in Section 4.5, a host-to-target adjustment for $\kappa$ is required when these GMPEs are used in a site-specific study. In an attempt to overcome this requirement, Laurendeau et al. (2013) introduce a term for $\kappa$ directly into a GMPE developed from Japanese data. Use of such a model means that $\kappa$ needs to be known for a site of interest. This is the apparent drawback of introducing new variables into GMPEs: the requirement for the user to know their value and their uncertainty for their study. In the past, however, the user generally assumed that the implicit average value within the data used to derive the GMPE was appropriate for their site.

\section{Regional models}

With the rapidly-growing quantity of data from digital strong-motion networks, which accurately record earthquakes down to $\mathbf{M} 3$ and below, there has been a move towards the development of GMPEs for small geographical regions (e.g. national or sub-national) and partially away from models covering large tectonic regimes, e.g. shallow crustal earthquakes globally. An idea of the utility of this approach for the development of empirical GMPEs 
Table 1: The number of years required to record fifty $M_{w} \geq 5$ shallow earthquakes assuming dense strong-motion network covering whole territory (country or state) based on the International Seismological Centre's earthquake catalog from 1992 to 2012.

\begin{tabular}{lr}
\hline Country & Number of years \\
\hline Japan & 7 \\
Turkey & 9 \\
Greece & 12 \\
California & 20 \\
Italy & 31 \\
Iceland & 140 \\
Spain & 250 \\
France & 1000 \\
United Kingdom & 1000 \\
\hline
\end{tabular}

given only data from a country or state can be gained from Table 1. For some highly seismically active areas this goal of purely-national GMPEs is feasible but for less active (e.g. Spain) or smaller countries (e.g. Iceland) local records would have to be used in conjunction with simulations or foreign data to derive robust models.

As discussed in Section 4.2, there are difficulties in developing regional models for use within standard seismic hazard assessments unless the models are derived using data from large events. Therefore, to account for potential regional dependency some GMPE developers derive a robust model using data from a variety of regions within a single tectonic regime (e.g. shallow crustal) and then add terms when required to account for observed regional differences. For example, Boore et al. (2014) include terms to model differences in anelastic attenuation in China/Turkey and Japan/Italy to other ar- 
eas (predominantly California). In addition to regional variations in median predictions, the variability of ground motion may be regionally-dependent. For example, Abrahamson et al. (2014) differentiate between variability in Japan and elsewhere.

Regional dependence of ground-motion models is, therefore, still a topic of ongoing research. The issue is somewhat complicated by the sweeping terms typically used to classify tectonic regions: stable continental, shallow active crustal and so forth. Within each of these groups significant variability in both structure and geology exists - meaning that systematic variability in ground motion may be obscured if only looking at differences within or between these classes. Nevertheless, it is generally acknowledged that at distances larger than around $50 \mathrm{~km}$, regional variations in geology and tectonic structure lead to significant differences in ground motion attenuation (e.g. Boore et al., 2013; Kotha et al., 2016b,a). On the other hand, differences at shorter distances are less well understood due to limited data and the complexity of earthquake sources. Regional differences in stress fields due to factors such as tectonic loading and structure (Gölke and Coblentz, 1996), or, at smaller scales, due to fault structure and maturity (Manighetti et al., 2007) may lead to differences in earthquake stress drop that can be observed at national (e.g. Goertz-Allmann and Edwards, 2014) or local scales (e.g. Allmann and Shearer, 2007). The resolution of such analyses is, however, debated due to the trade-off with attenuation, which is typically assumed to be homogeneous. Addressing the issue of regionalization of ground-motion models requires more data, particularly at short distances. In the meantime, hazard analysts can use hazard disaggregation to understand, to a first order, the sensitivity of possible regional ground motions on seismic hazard. For instance, hazard is often primarily driven by relatively close earthquakes 
$333(<50 \mathrm{~km})$ and, hence, regional differences in geology will be less important to understand than differences in fault-rupture kinematics, for example.

\subsection{Testing of GMPEs}

When conducting a seismic hazard assessment for a region that is not covered by a selected GMPE it has been increasing common to undertake a quantitative comparison between predictions and the ground motions observed in the region (Stewart et al., 2015). This has only become possible for many parts of the world since the advent of digital ground-motion networks in the past couple of decades. Various methods have been developed to undertake this testing but they are invariably based on 'residuals', either total or, more correctly, separated into between- and within-event components (Stafford et al., 2008), between predictions and observations. The most employed techniques are those by Scherbaum et al. (2004), Scherbaum et al. (2009) and Kale and Akkar (2013). A more informative approach is to consider plots of the residuals with respect to magnitude, distance and other variables to understand what parts of the model are causing any misfits (e.g. Scasserra et al., 2009).

A difficulty with such testing is that it is difficult to judge how much weight should be given to a good or poor match as the available data are often sparse and/or only available for magnitude and distance ranges of limited engineering interest (Beauval et al., 2012). If a poor match is found between observations and predictions and this is judged to be robust then adjustment factors can potentially be derived to modify the GMPE so that

\footnotetext{
${ }^{2}$ They are not strictly residuals because generally the data compared were not used for the derivation of the tested GMPE.
} 
it provides better predictions (Bommer et al., 2006). This approach has been formalized in the so called referenced-empirical technique by Atkinson (2010) and variants of it have been applied in various projects, particularly to adjust models for small and moderate events (e.g. Bourne et al., 2015).

\subsection{Scaling of ground motions for small and large earthquakes}

In the past decade there has been a push to derive GMPEs to predict accurately ground motions from earthquakes with $\mathbf{M}<5$. Until the establishment of digital strong-motion networks, which started in many regions in the late 1990s, ground-motion databases generally became sparse below about M5. In addition, for high seismicity areas, where most of the available data are from, the dominant earthquake scenarios for engineering purposes are generally at $\mathbf{M}>5.5$. Consequently there was little call for GMPEs that could be used confidently for small earthquakes.

The development of such models in the past decade has been driven by the availability of large sets of records from digital networks with good coverage down to often M3 for many parts of Europe and elsewhere. Often these data are used to derive regional GMPEs (see Section 4) generally without the inclusion of data from larger earthquakes. When applying a GMPE in a different geographical region than for which it was originally derived it is important to check it against local data. As shown by, for example, Douglas (2003b), unless the GMPE was derived using data from small events and an appropriate functional form was used there will likely be a large discrepancy between predictions and observations. This has been used as an argument for a strong regional dependency in ground motions but, as shown by Cotton et al. (2008) amongst others, it is likely due to the differing magnitude ranges of the observations and model. Another recent 
driver in the development of GMPEs that cover the range below M5, even for high seismicity zones, is the need for such models to estimate components of the ground-motion variability that require many records from the same site (see Section 5.3).

As shown by Douglas (2003b, Figure 4), Douglas and Jousset (2011) and Baltay and Hanks (2014), empirical GMPEs derived from data from small earthquakes generally show higher dependency on magnitude, particularly for short-period IMs, than those models derived for moderate and large events. This means that extrapolation of these models beyond the magnitude range for which they were derived often leads to over-prediction. Fukushima (1996), Douglas and Jousset (2011) and Baltay and Hanks (2014) demonstrate that a simple stochastic model (Boore, 2003) with a singlecorner source spectrum (Brune, 1970) and high-frequency attenuation (Anderson and Hough, 1984) reproduces the observed magnitude-scaling of empirical GMPEs and demonstrates why extrapolation of such models is so problematic. Algorithmic differentiation (Molkenthin et al., 2014) can be used to study the scaling of GMPEs with respect to its input parameters, which aids understanding of how the models behave and extrapolate.

As well as magnitude-scaling being different for ground motions from small and large earthquakes, the decay with distance also differs. Earthquake magnitude has two effects on the distance dependence of groundmotion attenuation. The first is due to near-field saturation: as one approaches a finite source, the contribution from the far ends of the source become increasingly small due to the distance that the energy must propagate to reach you (attenuation effects) and the time which this takes (scattering and dispersion effects). At short and moderate structural periods, therefore, the peak amplitudes of a $\mathbf{M} 7$ event are similar to an $\mathbf{M} 8$. The 
421

primary difference is the duration and spatial extent over which the motions occur, being significantly longer and more widespread in the latter case. The second effect is the distance dependence of the ground motion decay. For increasingly large events the finite nature of the source means that ground motion does not decay as quickly as for small (roughly point) sources, since the motion at distance is increased by constructive interference from later arrivals along the finite fault (e.g. Boore, 2009). In fact, even for point-source models, Cotton et al. (2008) showed that the decay of response spectral ordinates is magnitude-dependent due to the influence of spectral shape. To capture this, functional forms of GMPEs in the past decade have often used magnitude-dependent decay terms.

\subsection{Non-tectonic earthquakes}

Although the vast majority of GMPEs are still derived for tectonic earthquakes, a growing number of models are available for earthquakes of other types, e.g. those induced by mining (e.g. McGarr and Fletcher, 2005) or fluid injection (e.g. Douglas et al., 2013). Seismic hazard assessments for human-activity-related, induced or triggered earthquakes require groundmotion models that are adapted to this type of event and it is not a priori clear that shaking from such shocks is similar to that from natural earthquakes. In addition, the magnitude, source-to-site distance and focal depth range of importance for induced seismicity is generally smaller than the focus of hazard assessments for natural earthquakes. Hence, as discussed in Section 4.2 , this leads to the need to develop models to account for this difference. The finding of Douglas et al. (2013) that motions from induced and natural shallow seismicity are statistically similar means that the more abundant data banks of records from small natural shallow earthquakes could be 
used to derive GMPEs for use within hazard assessments for induced seismicity (e.g. Atkinson, 2015). It could also be argued that with an appropriate correction for depth [i.e. for distance and stress-drop (Hough, 2014)], data from deeper natural seismicity could be used to determine ground-motion fields of larger induced events.

\subsection{Prediction for a reference velocity horizon}

Ground motion within PSHA is typically estimated for a reference site, circumventing the geological heterogeneity of the uppermost layers. This is often at or around the NEHRP class B/C boundary of $760 \mathrm{~m} / \mathrm{s}$ or the Eurocode 8 class A/B boundary of $800 \mathrm{~m} / \mathrm{s}$ (e.g. Delavaud et al., 2012). Subsequently, the results of microzonation or site-specific response analyses can be applied in conjunction with these estimates. The reason for this is the significant variability of resolution, reliability and availability of site-specific data. Practitioners are, in this way, free to apply their own site specific corrections to a regionally-consistent hazard map for reference rock.

Site response terms within GMPEs are included for two reasons. Firstly, to enable ground-motion records from all site conditions (including nonrock stations, which comprise the majority of most strong-motion networks) to be used to derive GMPE that would be statistically more robust than using only rock records. A few developers (e.g. Idriss, 2014) exclude records from sites with low $V_{s, 30}$ because they believe that it is not possible to capture site response by means of a simple site term. Consequently such models are generally based on far fewer records but the risk of bias from site amplification is reduced. The second reason for including site terms in GMPEs is that such models allow seismic hazard assessments for a variety of sites (including non-rock sites) to be easily conducted, which could be 
useful when high accuracy is not a requirement.

In a similar way, recent PSHAs (e.g Bommer et al., 2015) predict the ground motion initially at a subsurface reference rock horizon, choosing a depth below which lateral variability is considered insignificant (usually at a wave velocity consistent with 'engineering' or hard rock). Site-specific nonlinear amplification is then applied during the hazard calculation based on site-response analyses. This approach has the benefit of potentially reducing the site-to-site variability in predicted ground motion. If one assumes the full range of site variability is captured through this process then the GMPE component of site-to-site variability $\phi_{S 2 S}$ (see Section 5.3) can be set to zero, leading to non-ergodic single-station sigma (Atkinson, 2006). Practitioners must be careful in this case that the modeled variability of the site response is sufficient, but at the same time not so high that ergodic $\sigma$ s are exceeded due to uncertainty in site response analyses.

The move towards reference-site hazard and reference horizons to make best use of site-response analyses means that GMPEs are being increasingly evaluated for relatively high $V_{s, 30}$ (e.g. $\geq 760 \mathrm{~m} / \mathrm{s}$ ). This is one of the factors driving the derivation of new GMPEs. Sites with high $V_{s, 30}$, however, are poorly represented in strong-motion databases because many stations are installed in urban environments on soft and stiff soils (e.g. Akkar et al., 2010).

\subsection{Host-to-target adjustments}

Ground motion is dependent on the shear-wave velocity and attenuation characteristics of the upper layers of soil and rock. When modifying site conditions, e.g. changing predictions relevant for California to a site-specific target in the United Kingdom, hazard analysts must consider the effect of 
this change on the predicted ground motion. This is done through host-totarget adjustments.

As stated above, GMPEs are typically developed using site descriptors such as class (e.g. rock, stiff soil and soft soil) or $V_{s, 30}$. It is important to note, however, that when using a GMPE estimates are implicitly tied to a range of possible site types that fall within the site descriptor and this may be biased by a particular geology. Even GMPEs using $V_{s, 30}$ will cover a range of site types because many velocity profiles are possible for a given $V_{s, 30}$. While different velocity profiles can lead to the same $V_{s, 30}$, they may lead to significantly different amplifications (e.g. Castellaro et al., 2008; Papaspiliou et al., 2012). If a particular velocity structure (e.g. low velocity soils over a high velocity basement) is characteristic of a region, then ground motion at a $V_{s, 30}$ in one region may be systematically different to that in another with a different average structure. As discussed previously, some of this site variability can be captured by using additional site parameters, such as $Z_{1.0}$ or $Z_{2.5}$. Recent PSHA studies have, however, moved towards fully accounting for the effect of site-specific characteristics, by taking advantage of the wealth of information often available for site-specific hazard analyses. Such differences are accounted for by using host-to-target adjustments. The same approach can be used to modify ground-motion predictions made at a particular $V_{s, 30}$ and provide them at another. This approach is particularly useful in the case that GMPE predictions are considered unreliable at the target $V_{s, 30}$.

Since earthquake engineering generally uses SA, direct adjustments of the Fourier amplitude spectra (FAS) cannot be used to perform host-to-target adjustments. This is because ground motion at a given oscillator period is dependent not only on the FAS at that period but also other values around 
it (e.g. Bora et al., 2015). The host-to-target ratio is, therefore, dependent on the input ground motion in addition to the different site properties. The hybrid-empirical method (HEM) based on Campbell (2003) is commonly used to make host-to-target adjustments. HEM uses stochastic simulations [typically using random-vibration theory (RVT) (Cartwright and LonguetHiggins, 1956)] to generate FAS-compatible response spectra for the host and target sites, which can then be used to calculate the ratio in terms of SA.

Using RVT through the HEM allows transformations from the Fourier domain into the response spectral domain. HEM, however, requires a full seismological model (for source, path and site) of the host and target regions. Because of this Al Atik et al. (2013) developed a method based on inverse RVT (IRVT) (Vanmarcke and Gasparini, 1976) that can be used to modify response spectra for host-to-target adjustments in the Fourier domain. The method has the advantage that no assumptions on the form of the host model (GMPE) are required. Working in the Fourier domain has the advantage that adjustments are independent of the input motion unlike when working in the response spectral domain. For a given signal duration (often defined based on simple regional models), IRVT transforms the response spectrum into a compatible FAS. FAS based host-to-target conversion can then be applied to the response-spectrum-compatible FAS before being returned to the response domain through the standard RVT approach. A limitation of the IRVT approach is that the response spectrum becomes less sensitive to the FAS as oscillator period decreases. This results in significant non-uniqueness of the response-spectrum-compatible FAS at short periods (roughly $T<0.05 \mathrm{~s}$ ). Nevertheless, an advantage of this approach is that one can directly estimate seismological parameters from the 
GMPE-compatible FAS, such as $\kappa$.

Figure 2 shows an application of the $V_{s^{-}} \kappa_{0}$ corrections to GMPEs used in the Swiss National Seismic Hazard Maps (Edwards et al., 2016). The selected target $V_{s}$ profile (Poggi et al., 2011, $V_{s, 30}=1105 \mathrm{~m} / \mathrm{s}$ ) and $\kappa_{0}$ value (Edwards et al., 2011, $\kappa_{0}=0.016 \mathrm{~s}$ ) define the reference rock for the seismic hazard map. For each GMPE two possible host $V_{s}$ profiles were selected (with defined $V_{s, 30}$ where the GMPE's developers considered the best data coverage for rock). Four $\kappa_{0}$ values were also selected for each GMPE using either $V_{s, 30} \kappa_{0}$ correlations or direct measurement using IRVT. The resulting eight $V_{s}-\kappa_{0}$ corrections for each GMPE were considered to represent the epistemic uncertainty involved in adjusting GMPEs to the regional reference. Small but significant differences arise at long periods due to differences in amplification of the host- $V_{s}$ profiles. Far more significant, however, is the epistemic uncertainty evident in the correction at short periods $(T<0.1 \mathrm{~s})$, which is due to the uncertainty in defining $\kappa_{0}$ (e.g. Edwards et al., 2015). Similar observations are made by Rodriguez-Marek et al. (2014) for a sitespecific hazard assessment.

\section{Aleatory variability}

Over the past decades there has been a growing realization that predicting shaking in future earthquakes is associated with large uncertainties and that this uncertainty must be captured within seismic hazard assessments. It has become standard to split these uncertainties into two components: those of inherent randomness, referred to as aleatory variability (this section) and those relating to a lack of knowledge or understanding, referred to as epistemic uncertainty (Section 6). 

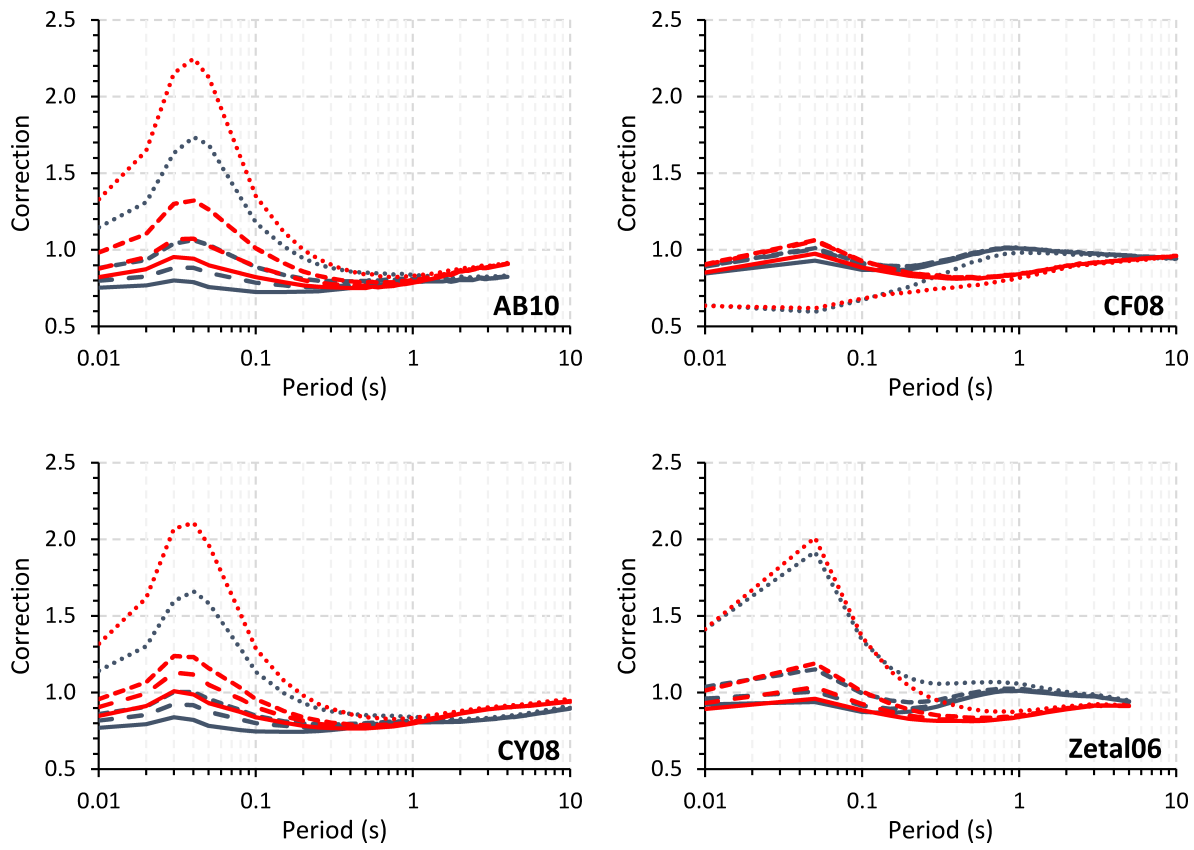

Figure 2: $V_{s}-\kappa_{0}$ corrections proposed for the Swiss National Seismic Hazard Maps by Edwards et al. (2016). Blue/Red indicate different host $V_{s}$ profiles (two for each GMPE), line types indicate different $\kappa_{0}$ (four for each GMPE) resulting in eight possible corrections per GMPE. AB10: Akkar and Bommer (2010); CF08: Cauzzi and Faccioli (2008); CY08: Chiou and Youngs (2008); and Zetal06: Zhao et al. (2006). The target properties are $V_{s, 30}=1105 \mathrm{~m} / \mathrm{s}$ and $\kappa_{0}=0.016 \mathrm{~s}$. 
The definition of aleatory (and consequently epistemic) variability inevitably leads to disagreement and confusion. It could be argued, for instance, that given a perfect model, aleatory variability is, by definition, zero. However, in current understanding we can at least separate the variability into parts that can be quantified in terms of scientific uncertainty (e.g. using different models to predict the same phenomena, such as site amplification), and those for which there is (at least currently) no scientificallybased predictive capability (e.g. the stress-drop of the next earthquake). A more appropriate terminology may therefore be apparent aleatory variability with respect to a chosen model (written communication, J. J. Bommer, 2016). The advantage of splitting uncertainty into constituent components is that the logic-tree approach (Kulkarni et al., 1984) can then be used to branch through the epistemic uncertainty space (e.g. by selecting and weighting different models) and allowing site or region-specific selections to be made along with sensitivity studies and analyses (e.g. disaggregation) at a branch-by-branch level. The distinction between aleatory and epistemic is particularly important, for example, in the case of a fully probabilistic seismic risk (or safety) assessment for a safety critical structure such as a nuclear power plant. Such assessment requires the fractiles of the hazard to be defined, which can only be correctly calculated with an appropriate separation of aleatory and epistemic uncertainty.

Following Douglas (2003a), Strasser et al. (2009) observe that $\sigma$ associated with GMPEs has shown little or no decrease since the 1970s despite the increasing complexity of models. This fact and the importance of $\sigma$ on the results of PSHAs at long return periods, has encouraged attempts to increase the complexity of models to account for other effects than simply magnitude, distance and site class (see Section 3). To date these attempts 
have not led to significant reductions in $\sigma$ because GMPEs remain simple representations of complex physical phenomena. Improvements to metadata do, however, lead to slight reductions in assessed $\sigma$. For example, the model of Chiou and Youngs (2014) is associated with a smaller $\sigma$ when measured $V_{s, 30}$ is used for a site than when an estimate of this site parameter is employed.

One of the major areas of engineering seismology research in the past decade has been in separating $\sigma$ into its different components (Al Atik et al., 2010; Lin et al., 2011; Rodriguez-Marek et al., 2013) and using the appropriate components when conducting a hazard assessment (e.g. Walling and Abrahamson, 2012). There has also been a move from using whatever data were available towards selecting to: limit bias, exclude unreliable data, make analysis easier, and obtain more reliable $\sigma$ estimates. As noted above, it has become standard to use random-effects/maximum-likelihood methods to estimate between-event $(\tau)$ and within-event $(\phi)$ components.

Records from nearby sites are correlated, which has been recognized by Jayaram and Baker (2010) when developing a regression technique to account for spatial correlations and by Boore et al. (1993), who choose only a single record per site class within a radius of $1 \mathrm{~km}$. These spatial correlations are also important when conducting PSHA for infrastructure with considerable spatial extent or when computing group earthquake risk over an extended area.

\subsection{Between-event variability}

Aleatory variability within a given GMPE is usually separated into between- and within-event components ( $\tau$ and $\phi$, respectively). Betweenevent terms (random-effects in the context of random-effects regressions), 
which are source-specific, are thought to be mainly related to stress drop (Cotton et al., 2013). Using stochastic simulations, Drouet and Cotton (2015) showed that the between-event variability was strongly controlled by the stress parameter (as noted previously, 'stress parameter' is used to avoid physical interpretation in terms of pure 'stress drop' and rather indicate the proportion of high-frequency energy radiated by an earthquake). The between-event term can, therefore, be thought of as describing how energetic the rupture was compared to the average for a given magnitude (all other things being equal). Such features are not possible (currently) to predict and, therefore, fall into the category of aleatory variability. The standard deviation of these event terms is described by $\tau$.

One of the main ways GMPEs are improving is related to the recording of each earthquake by an increasing number of stations (in particular, fewer singly-recorded events) so that the source terms (and $\tau$ ) are better constrained. This is particularly true for models based on predominantly Californian or Japanese data but much less so for models derived from data from Europe and the Middle East (Table 2 and Figure 3). This shows that despite recent improvements in strong-motion networks in Europe and Middle East, strong motion databases there remain dominated by poorlyrecorded events. For models based on data with low record-to-event ratios the source terms (e.g. style-of-faulting factors) and $\tau$ are poorly constrained. Additionally, the small number of well-recorded events have a strong influence on the model.

$\tau$ is often found to be heteroscedastic, with decreasing variability as magnitude increases (e.g. Youngs et al., 1995) (Figure 4). Estimated groundmotion variability from small events $(\mathbf{M}<5)$ is often significantly larger than at moderate and large magnitudes, with many GMPE developers avoid- 


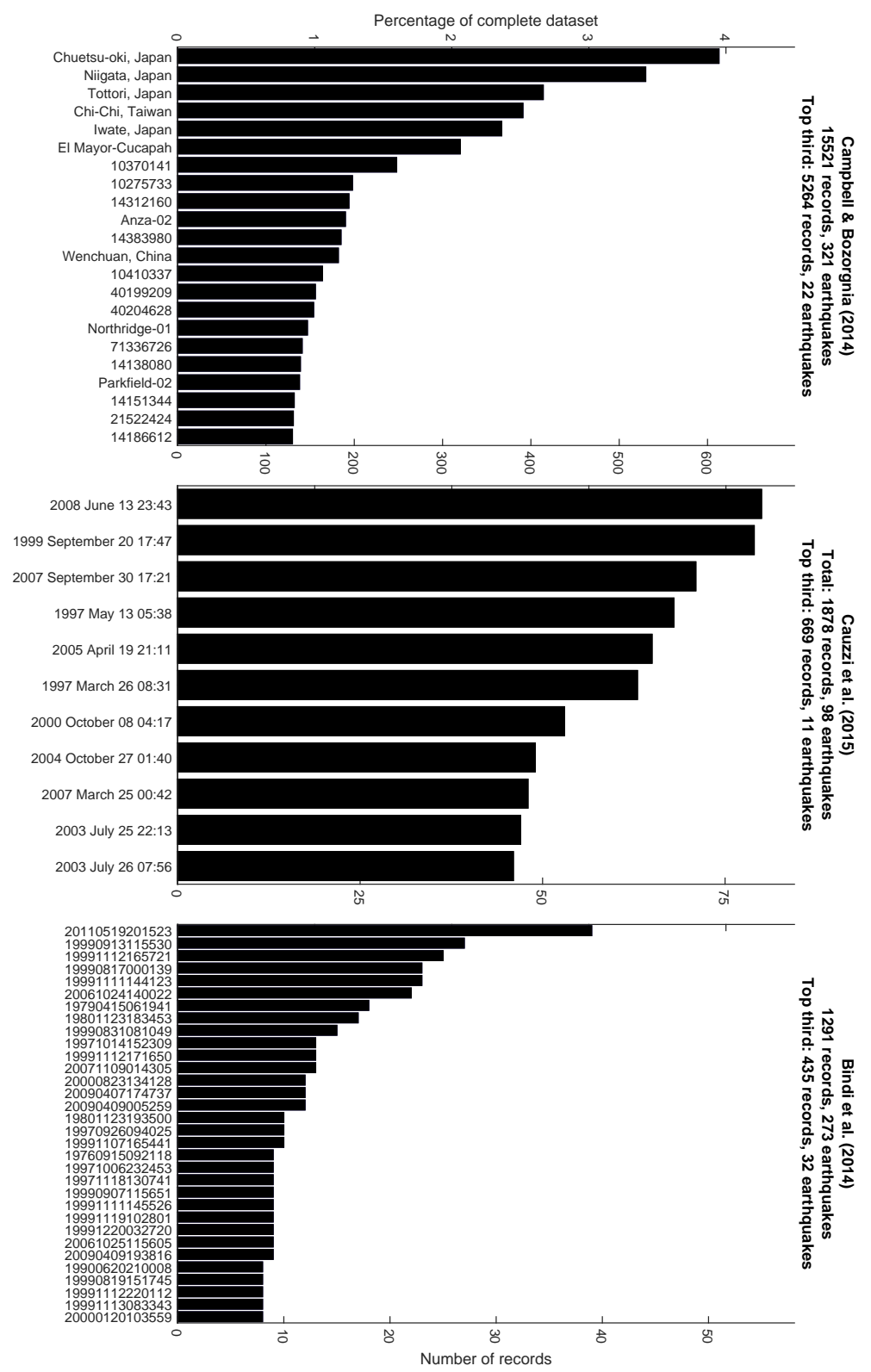

Figure 3: Number of records (bottom axes, different scales for all three subplots) and percentage of total (top axes, same scales for all three subplots) from earthquakes contributing to the top third of total number of records to three recent GMPEs: Campbell and Bozorgnia (2014) (predominantly Californian data), Cauzzi et al. (2015) (predominantly Japanese data) and Bindi et al. (2014) (European and the Middle Eastern data). 
Table 2: Ratio (R/E) of number of records (R) per event (E) for four generations of 'Californian' and 'European' models.

\begin{tabular}{lrrr|lrrr}
\hline 'Californian' model & $\mathrm{R}$ & $\mathrm{E}$ & $\mathrm{R} / \mathrm{E}$ & 'European' model & $\mathrm{R}$ & $\mathrm{E}$ & $\mathrm{R} / \mathrm{E}$ \\
\hline Joyner and Boore (1981) & 182 & 23 & 8 & Ambraseys and Bommer (1991) & 529 & 219 & 2 \\
Boore et al. (1997) & 271 & 20 & 14 & Ambraseys et al. (1996) & 422 & 157 & 3 \\
Boore and Atkinson (2008) & 1574 & 58 & 27 & Ambraseys et al. (2005) & 595 & 135 & 4 \\
Boore et al. (2013) & $\sim 15000$ & $\sim 350$ & 43 & Akkar et al. (2014a) & 1041 & 221 & 5 \\
\hline
\end{tabular}

ing using data from small earthquakes. This is despite the need for models at lower magnitudes, e.g. for seismic hazard assessment from induced seismicity, to examine the applicability of a GMPE in a new region and to study the various components of ground-motion variability. While models of ground-motion variability have improved significantly in recent years, we must be careful not to over-interpret features of these models due to the limitations of separating the different contributions. In Figure 4 there is a peak at $0.1 \mathrm{~s}$ for several models which is difficult to understand in terms of source variability. During the Hanford PSHA (Hanford.gov, 2014) this was demonstrated to be an effect of sampling different ranges of site response from event to event. The site variability is, therefore, mapped into between-event terms leading to the peak at $0.1 \mathrm{~s}$.

Arguments for observing lower variability at large magnitudes include the fact that meta-data for large events (e.g. magnitude, depth and mechanism) are more reliable. While this is, in general, true, there has been significant work in recent years to develop reliable earthquake catalogs for smaller events. Another argument is that, due to large earthquakes having large rupture sizes, the sensitivity of ground motion to, for example depth or magnitude, is less. For example, $\mathbf{M}<5$ events can generally be assumed to be point sources, with amplitudes decaying in proportion to the reciprocal of hypocentral distance. On the other hand, $\mathbf{M}>6$ events emit waves from a 
range of sources along several kilometers of rupture. Increasing the depth or size of this fault, whilst changing the distance over which some of the seismic energy must propagate, will, therefore, have a reduced effect. This is evident in the saturation of ground-motion amplitudes for increasing magnitude in GMPEs. Having reliable meta-data for larger events is, therefore, arguably less important than for small earthquakes for sites not close to major active faults. For other locations, reliable information on fault geometry and other properties (e.g. rupture mode) is vital when estimating near-source ground motions.

The limited number of events at large magnitudes leaves $\tau$ open to undersampling (with each event only contributing a single data-point to the estimate of $\tau$ ). Given that strong-motion databases often include only a handful of well-recorded events with $\mathbf{M}>7$, the reliability of heteroscedastic $\tau$ can be called into question. Comparing values from different GMPEs we can see that the variability in $\tau$ estimates is rather high (Figure 4 ). In reality, $\tau$ is likely to be heteroscedastic, but caution should clearly be applied in using low values at $\mathbf{M}>7.5$ coming from extrapolation of trends from smaller magnitudes (Musson, 2009). Models developed with constant $\tau$ estimates for $\mathbf{M}<5$ and $\mathbf{M}>7$ connected by a linear trend (e.g. Abrahamson et al., 2014) are an appropriate compromise in this sense.

\subsection{Within-event variability}

Ground-motion variability with respect to a given GMPE for single event is described by within-event variability $(\phi)$. It can be interpreted as describing the standard deviation of the misfit between GMPE and data after accounting for the between-event terms. In terms of the random-effects framework, $\phi$ describes the standard deviation of within-event random-effects. 

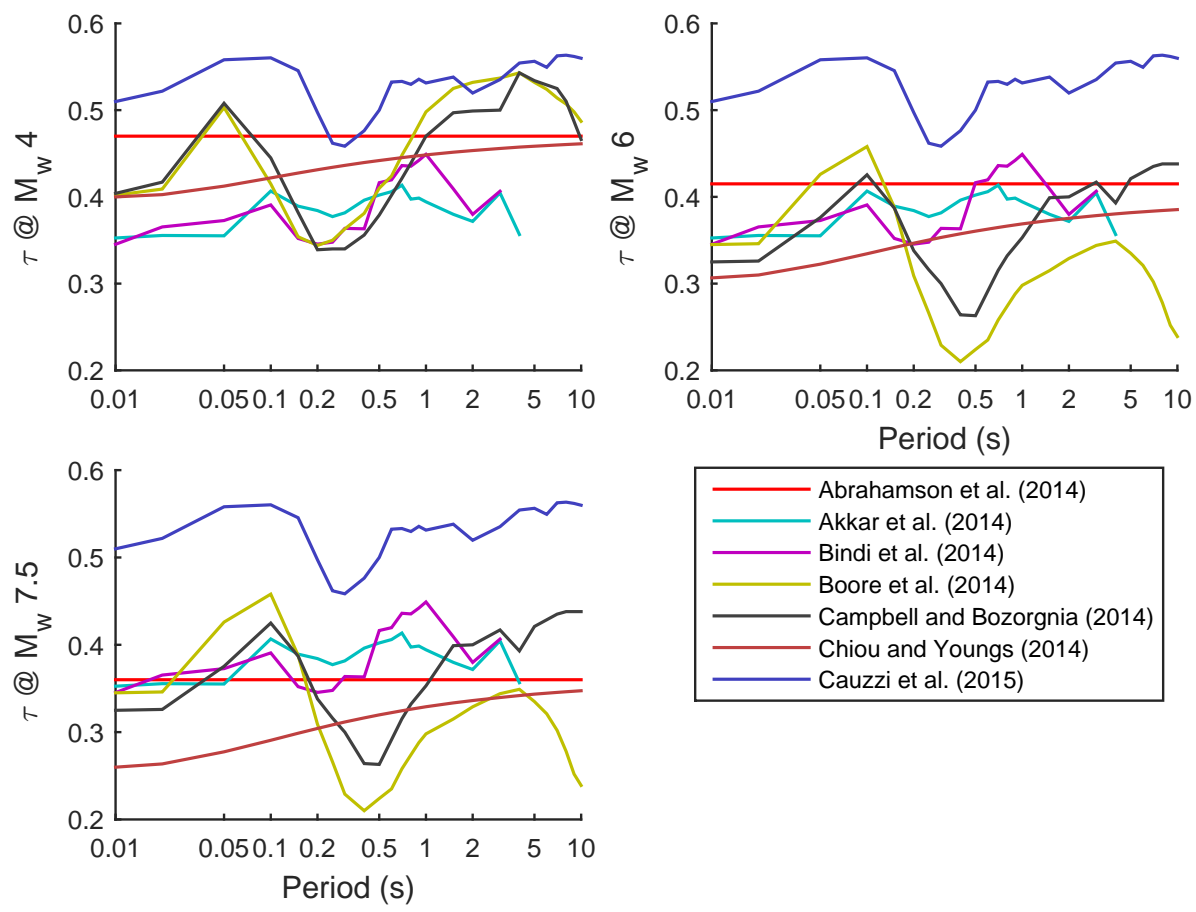

Figure 4: Comparison of the $\tau$ models of six recent GMPEs: Abrahamson et al. (2014), Boore et al. (2014), Campbell and Bozorgnia (2014) and Chiou and Youngs (2014) (predominantly Californian data); Bindi et al. (2014) and Akkar et al. (2014a) (European and the Middle Eastern data); and Cauzzi et al. (2015) (Japanese data), for M4, 6 and 7.5 with respect to response period. 
The logarithm of ground-motion variability is assumed to be normally distributed. The total variability of a dataset with respect to a GMPE is then given by (assuming independence between the two components): $\sqrt{\tau^{2}+\phi^{2}}$. Within-event variability is related to path and site phenomena in addition to any spatially-dependent source characteristics, such as radiation pattern or directivity effects. Because of the dominant effect of site amplification and the significant variability of site effects these are considered to be a significant source of within-event variability (e.g. Rodriguez-Marek et al., 2011). In the most recent studies, $\phi$ is therefore split into components describing site-to-site variability $\left(\phi_{S 2 S}\right)$ and within-site variability $\left(\phi_{0}\right)$. Drouet and Cotton (2015) showed that the within-event variability is controlled by a number of factors: the most significant being site amplification/attenuation effects (including $\kappa$ ) followed by path effects, such as geometrical and anelastic attenuation. Bindi et al. (2014) observe that certain stations contribute a large proportion of the soft soil (Eurocode 8 class D) sites for European GMPEs. Some often-triggered stations, therefore, have strong influence on the model and may reduce the apparent within-event variability.

While $\phi$ is often considered a 'site term' it is also observed to be magnitude, distance and $V_{s, 30}$ dependent (Figure 5). For instance, Boore et al. (2014) and Campbell and Bozorgnia (2014) show that $\phi$ decreases with magnitude at short periods and increases with magnitude at long periods. Due to the interaction of ergodic and non-ergodic components of variability it is difficult to know if this is truly a site-specific effect or due to site-to-site variability (different sites having recorded different ranges of earthquake magnitudes and distances). An effective magnitude-distance dependence of $\phi$ due to nonlinearity of soil response has been incorporated into GMPE development. For example, Abrahamson et al. (2014) account for soil non-linearity 

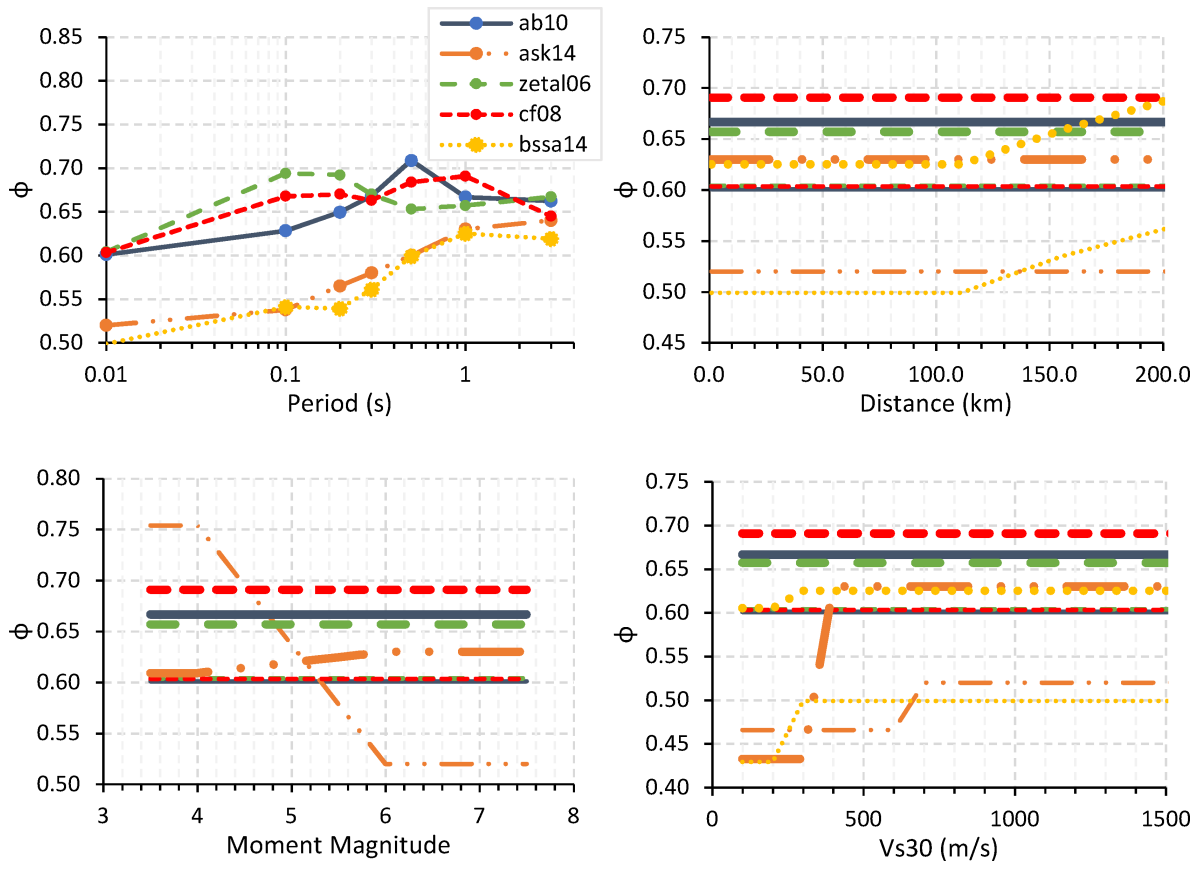

Figure 5: Comparison of estimates of the within-event variability $\phi$ from some recent GMPEs, where ab10 corresponds to Akkar and Bommer (2010), ask14 corresponds to Abrahamson et al. (2014), zetal06 corresponds to Zhao et al. (2006), cf08 corresponds to Cauzzi and Faccioli (2008) and bssa14 corresponds to Boore et al. (2014).

reducing the variability of short-period motions. Focusing on non-ergodic sigma, Rodriguez-Marek et al. (2013) present models for single-station $\phi$ using data from various tectonic regions. They show a decrease of singlestation $\phi$ over all periods, which differs from the observations of ergodic variability, where long-period motions show increased $\phi$ for large earthquakes.

An explanation for the different observations of $\phi$ 's dependency on distance and magnitude may be found in the dependence of response spectral amplification on the input motion (e.g. Bora et al., 2016). Given that resonance effects in site response depend greatly on the site type (e.g. longperiod resonance for deep sedimentary basins and high-frequency resonance 
for thin deposits of alluvium), whether or not input motions (broadly defined by magnitude and distance) excite a particular resonant frequency will make a difference to ground-motion variability. As a result, depending on the characteristic site type(s) in a strong-motion database, the sensitivity of $\phi$ to magnitude and distance will vary. Rock, or hard-rock sites, will be mostly independent of input motion, while soil and stiff-soil sites will be strongly dependent on the input motions, with nearby smaller-magnitude (higher-frequency) events strongly amplified by high-frequency resonance peaks.

\subsection{Single-station variability}

The ergodic assumption has been used to derive most GMPEs to date (Figure 6). This assumption is made to overcome the fact that limited data are available at individual stations and to provide average (e.g. azimuthindependent) predictions. The ergodic assumption assumes that spatial variability can be mapped into variability in time (Anderson and Brune, 1999). Given that station-to-station variability is a significant component of aleatory variability captured in GMPEs, this assumption cannot be valid for a single site. To overcome this limitation, the concept of single-station variability was introduced by Anderson and Brune (1999) and first estimated using a large set of data by Atkinson (2006). $\sigma_{S S}$ describes the total variability (within- and between-event) in SA expected at a single site. Provided ground-motion variability is separated into $\phi_{0}$ and $\phi_{S 2 S}$ then simply setting $\phi_{S 2 S}$ to zero will result in $\sigma_{S S}$. Rodriguez-Marek et al. (2013) showed that $\sigma_{S S}$ shows remarkably little variability between regions thereby suggesting that it is the site-to-site variability that drives differences in ground-motion variability between regions. Although recent work by Al Atik (2015) evi- 
denced slightly higher values of $\sigma_{S S}$ based on data from the stable continental region of central and eastern North America.

While $\sigma_{S S}$ reduces the variability to that consistent with what would be observed given sufficient recordings at a single site, we must be careful that the GMPE used for the single site is not biased. When GMPEs are derived using data from a variety of sites they invariably produce output that is consistent with the average site within a given site class or for a given $V_{s, 30}$ in the dataset. $\phi_{S 2 S}$ then accounts for the variability between sites. However, if we are just looking at one site and using $\sigma_{S S}$ we must ensure that the GMPE produces a median consistent with our study site. For this reason host-to-target adjustments (Section 4.5) may be used.

Building on current practice of using mixed-effects regression to determine GMPE coefficients (Abrahamson and Youngs, 1992), Stafford (2014) presents the use of crossed and nested mixed effects to determine robust models that are not subject to the short comings of multi-stage approaches often adopted to separate model components. Using this approach he shows how site- and region-specific effects can be accounted for within a single inversion.

\section{Epistemic uncertainty}

Despite rapidly increasing strong-motion databases and the considerable improvements in our understanding and modeling of strong ground motions (see above) each new GMPE published invariably predicts different levels of average shaking and its variability for every scenario than previous models. These differences arise from epistemic uncertainty, although generally this uncertainty is larger than these differences imply. If we had 
Ideal Scenario

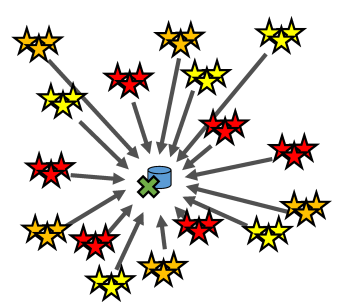

\3arget Site $\Theta$ Recording Site $\ominus$ Recording Site Earthquake
Ergodic Assumption

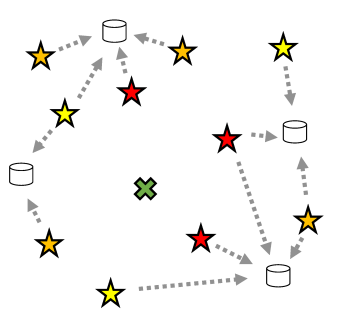

Site Corrected ...V Variable-station/path Record
Single Station Sigma

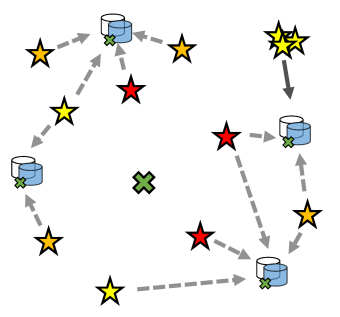

Figure 6: Sketch of transition from ergodic to (partial) non-ergodic assumption. Earthquakes of the same magnitude but with different characteristics (e.g. stress parameter) are indicated by different colored stars. Left: ideal scenario, with numerous events being recorded at a single station. Full separation of uncertainties related to event characteristics $(\tau)$, and path and site characteristics $(\phi)$ is possible down to single-event-single-path $\sigma$. Center: typical scenario, with events sparsely recorded on regional network with various site types (e.g. $V_{s, 30}$ ). An ergodic assumption is used: time equivalent to space to define $\tau$ and $\phi$. Right: advanced approaches correct sites to account for differing response (singlesite $\sigma$ ), while multiple events on the same source (e.g. fault) allow single site-single-path $\sigma$ to be defined. 
an infinite amount of data available from every earthquake scenario, travel path and site then the epistemic uncertainty would reduce to zero as there would be no need for models, simply selection of the strong-motion records from the database appropriate for the required scenario. There may still be aleatory variability in this case because of intrinsic randomness in earthquake rupture, wave scattering and so forth but for a given scenario the true average ground motions and its variability should be defined exactly. Non-parametric methods (e.g. neural networks) are useful in investigating ground-motion scaling for well-sampled scenarios (e.g. Derras et al., 2014; Hermkes et al., 2014). Such data-mining approaches are likely to play an increasing role as strong-motion databases grow.

The day of sufficient observations to no longer require models is many decades, or even centuries, away for most scenarios of engineering interest. As shown by Douglas (2010b, 2012) average predicted ground motions for scenarios close to the barycenter of available data $\left(M_{w} \sim 6, R \sim 20 \mathrm{~km}\right)$ have remained roughly constant over the past few decades despite improvements to GMPEs. For well-observed regions such as western North America there has been some convergence in predictions (Douglas, 2010b). This is because the same data are used to tune the models. Predictions for scenarios closer to the edges of available observations (e.g. $M_{w}>7$ and $R<10 \mathrm{~km}$ ), however, display larger differences. One question that is rarely raised is: how representative are the available data of ground motions in that region? For example, are the few well-recorded $\mathbf{M}>7$ crustal earthquakes in strongmotion databases representative of all future large events? Re-sampling and bootstrap techniques to assess the stability of the models to the removal of data could be useful in this context (e.g. Berge-Thierry et al., 2003; Bindi et al., 2014). These approaches, however, only provide guidance on the im- 
pact of data that are already available and not on the stability of the models to future observations.

Another way of understanding epistemic uncertainties is to examine the statistical confidence limits (e.g. Draper and Smith, 1998) in the median predictions from a given GMPE (Campbell, 1985). This has been done by Douglas (2010a), who examined the width of the confidence limits from three generations of GMPEs for western North America (Joyner and Boore, 1981; Boore et al., 1997; Boore and Atkinson, 2008) and Europe and the Middle East (Ambraseys and Bommer, 1991; Ambraseys et al., 1996, 2005). Douglas (2010a) finds that the confidence limits for the western North American models are narrowing (and hence epistemic uncertainty is reducing) but that this is not seen for the models from Europe and the Middle East, which he relates to making the models too complex given the number of records available. Recently, Al Atik and Youngs (2014) compute confidence limits for the NGA West 2 GMPEs and propose a method to include this uncertainty within a seismic hazard assessment. A third way of examining similarities between models is to use high-dimensional information-visualization techniques, such as Sammon's maps (Scherbaum et al., 2010), that display models on a 2D graph thereby allowing identification of models that predict similar motions.

As strong-motion networks become denser the average number of stations that record a given earthquake increases, which means that model source terms (e.g. style-of-faulting factors) and the between-event variability $(\tau)$ are better constrained in recent GMPEs. Similarly a modern station generally records more earthquakes leading to better estimates of site terms and single-station $\sigma$. Site terms are now less biased since fewer stations contribute a large proportion of records to strong-motion databases, although 
the number of records per station remains highly variable.

The reduction of epistemic uncertainty (differences in predictions among models) remains a considerable challenge. It is vital that this uncertainty is not artificially reduced but that seismic hazard assessments correctly account for the true uncertainty in ground-motion prediction. There is a trade-off to be made between including more and more independent variables to seek to reduce $\sigma$ but thereby increasing epistemic uncertainty in the model because these variables are difficult to predict before an earthquake and because more variables require more data to constrain the free coefficients in the GMPE.

Only a few GMPE developers (e.g. Douglas et al., 2013) estimate the epistemic uncertainty in their models. Estimates of the lower bound of the epistemic uncertainty can be made by comparing multiple models by the same developer team or by various teams using the same master database (Douglas et al., 2014a; Abrahamson et al., 2008; Gregor et al., 2014). These comparisons do not capture the part of uncertainty related to the question: for which parts of the models are changes likely in the future because of lack of understanding or knowledge? The motto of US General Colin Powell: 'Tell me what you know. Tell me what you don't know. Then tell me what you think. Always distinguish which is which' may be useful in this context. The first and third parts of this saying are remembered by all GMPE developers but the second and last parts are often forgotten in the development of ground-motion models.

Logic trees (Kulkarni et al., 1984) are used within seismic hazard assessment to model epistemic uncertainty by assigning weights to each groundmotion model, for example, depending on the degree of belief that the hazard analyst has in that model being the appropriate one for the study (e.g. 
Bommer et al., 2005). Consequently there should be a correlation between the level of understanding about earthquake shaking at the study site (or regions) and the spread in predicted median ground motions from the logic tree: wider spread in predictions where knowledge is limited and reinforcing predictions where knowledge is greater. There is, however, evidence for 'group think' in models. For example, many of the predictions from the NGA models changed in the same way from 2008 (NGA West 1) to 2014 (NGA West 2), e.g. the predictions for earthquakes with $\mathbf{M}<5.5$ change considerably [and in agreement with what would be expected (Bommer et al., 2007)] but those for M7.5 change very little (Figure 7). Will such large changes to predictions also occur when more large earthquakes have been well recorded? When there are few observations it is uncomfortable to be out on a limb and for your model to predict greatly different motions than the majority of models. Consequently, things have changed where new data (e.g. small magnitudes) are added to strong-motion databases but not where uncertainty remains high, e.g. close to large events. This leads to the apparently inconsistent observation made by Douglas (2010b) that the divergence in predictions of median ground motions from GMPEs for stable continental regions is lower for large magnitudes (for which there are very few observations) than for small magnitudes (where data exist).

Since about 2010 there has been increasing use of the backbone approach (Atkinson et al., 2014) to model epistemic uncertainty in ground-motion prediction. In this approach, rather than use a suite of GMPEs to model epistemic uncertainty within a logic tree, a single GMPE (or sometimes two or three GMPEs) is scaled up and down by factors to generate a set of mutually-exclusive and collectively-exhaustive models. The backbone approach has the advantage of always having an overall ground-motion model 

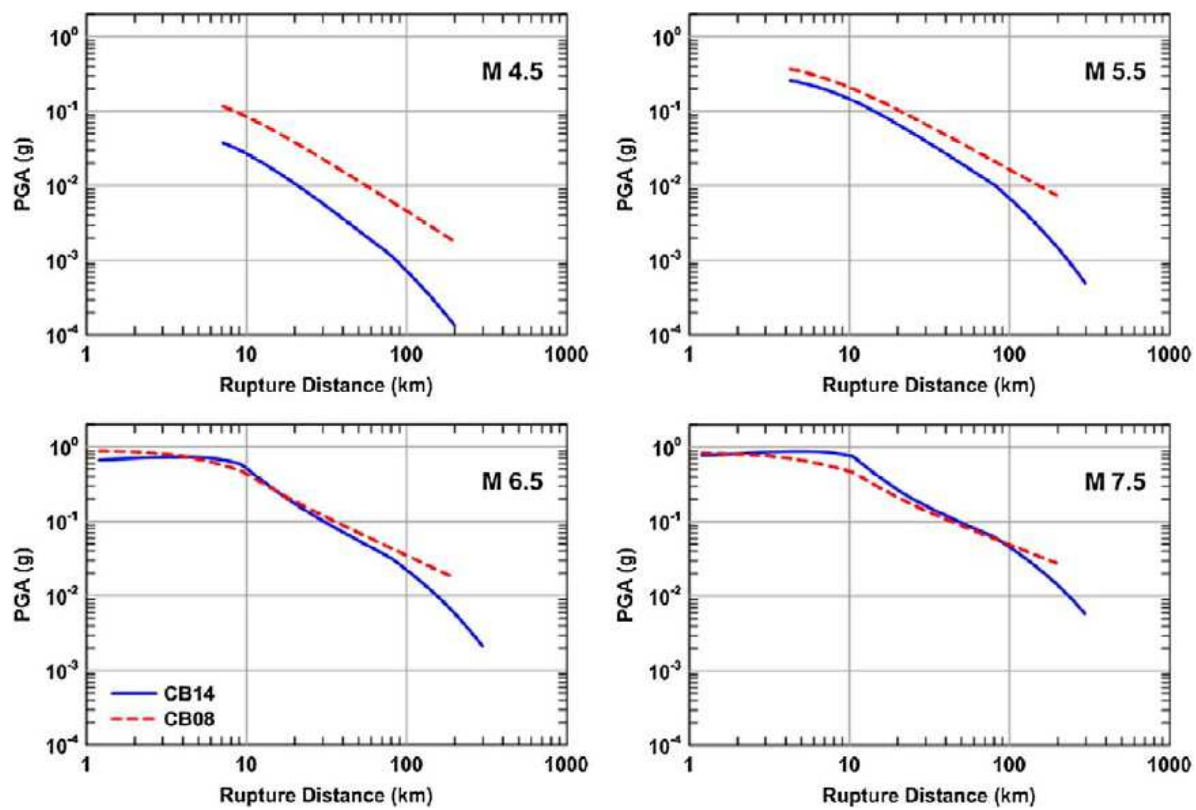

Figure 7: Comparison of predicted median PGA from Campbell and Bozorgnia (2008) (CB08) and Campbell and Bozorgnia (2014) (CB14) on a site with $V_{s, 30}=760 \mathrm{~m} / \mathrm{s}$ for M4.5 to 7.5 from $45^{\circ}$-dipping reverse fault. Figure taken from Campbell and Bozorgnia (2014) 
that allows the epistemic uncertainty to be defined directly by expert judgment, and which is explicitly definable. The multiple GMPEs approach, however, leads to varying modeled uncertainties, which may lead to pinch points for certain scenarios that may not be logical (e.g. where there are few data but the GMPEs coincide). The backbone approach, however, may lead to overestimation of epistemic uncertainties when data are abundant and it can be tricky to calibrate. On the other hand, the availability of abundant data is unfortunately not presently the case for all relevant scenarios (e.g. large magnitude near-source) and using only published GMPEs without any scaling factors will likely lead to underestimation of the true epistemic uncertainty.

\section{Extensions to ground-motion models}

As noted above, the vast majority of GMPEs have been derived for PGA and linear elastic response spectral ordinates (particularly for $5 \%$ of critical damping). Because of its proposed use in liquefaction analysis, its better correlation with felt and damage reports and its use in some regulations (e.g. Bommer and Alarcón, 2006) PGV has also become a popular IM for groundmotion models. In the past decade or so, there has been a growing interest in deriving models for other IMs (Douglas, 2012), in particular Arias intensity (Arias, 1970) [commonly used in the analysis of earthquake-triggered landslides (e.g. Harp and Wilson, 1995)], relative significant duration (Trifunac and Brady, 1975) and peak ground displacement. A handful of models for other IMs (e.g. Fourier spectral amplitudes, Japanese Meteorological Agency seismic intensity, cumulative absolute velocity, mean spectral period and inelastic response spectral ordinates) have also been published (Douglas, 
2016). Finally, there is a growing set of macroseismic intensity prediction equations (Cua et al., 2010). These allow PSHA to be conducted directly for IMs that have various engineering uses rather than having to conduct a seismic hazard assessment for PGA, for example, and then convert this to the required IM. This should lead to smaller overall uncertainties within risk assessments.

Standard GMPEs predict independent scalar IMs. This is what is required by PSHA to compute uniform hazard spectra, for example. Recent developments in earthquake engineering, e.g. conditional mean spectra (Baker, 2011), mean that it is important to know the correlation between spectral ordinates at different structural periods (e.g. Baker and Jayaram, 2008) and between various IMs (e.g. Bradley, 2011). Consequently models for the estimation of these correlations have been derived. These provide a more complete assessment of earthquake ground motions.

Another way in which the picture of earthquake shaking is becoming richer is through the derivation of models to estimate the spatial correlation of motions between neighboring geographical locations (e.g. Goda and Hong, 2008). Such models improve the accuracy of earthquake loss predictions of spatially-distributed portfolios (e.g. Weatherill et al., 2015).

\section{Conclusions and ways forward for ground-motion prediction}

A number of multinational projects have, over the last decade, brought significant advances in ground motion characterization for seismic hazard analyses. These include the NGA West 1 and 2 (Power et al., 2008; Bozorgnia et al., 2014), NGA East (Pacific Earthquake Engineering Research Center, 2015) and RESORCE (Akkar et al., 2014b) projects. In addition to 
these initiatives, numerous peer-reviewed articles have improved our knowledge and understanding of ground-motion prediction in a variety of regions, from active regions with high seismicity (mainly empirical GMPEs) to stable continental regions with low seismicity (with focus on robust simulation approaches, such as stochastic methods). Despite the significant investment over the last decades, the aleatory variability in ground-motion prediction for scenario events appears not to have decreased (e.g. Strasser et al., 2009). Nevertheless, our understanding of the source and behavior of ground-motion variability has improved dramatically, with articles barely mentioning it 20 years ago, to the current state where sometimes roughly half of a manuscript presenting a new GMPE is dedicated to its characterization. While the total variability is therefore not reduced, the way in which it is implemented in hazard models is now more realistic. The biggest improvement is arguably the shift from ergodic towards non-ergodic variability. This has reduced the $\sigma$ used within site-specific (or reference-specific) hazard analyses by as much as $30 \%$.

Despite the great advances of recent years, ground-motion characterization is still very much a topic in development. Some authors (e.g. Atkinson, 2012) have predicted that the goal is for numerical simulations to be performed to estimate ground motion and its variability. Despite the increase in computing power allowing the calculation of shorter-period ground motions (with current limits around 0.3 to $1 \mathrm{~s}$ ), the limitation of simulations is twofold. Firstly, they rely on geophysical characterization of the crust and shallow subsurface, but at short-periods $(<1 \mathrm{~s})$ the resolution scale of most available geophysical models is simply insufficient. To overcome this limitation, so-called hybrid approaches are used, where stochastic simulation models are implemented to some cross-over period (e.g. Graves and Pitarka, 
2010). Such methods clearly have the same limitations of existing empirical and stochastic models at short periods. Purely deterministic numerical simulations are still, therefore, at least several years away. The second limitation of numerical simulations is the understanding of constituent parameters and their covariances. Engineering practice requires stable and repeatable models, which GMPEs provide. While numerical simulations can be calibrated to provide predictions consistent with observed earthquake shaking, in practice the input parameters are poorly understood meaning that naive simulations may be incorrect.

Before purely deterministic numerical scenario-simulations become possible the most promising developments in PSHA lie with the understanding of ground-motion variability, which drives hazard at long return-periods. The conceptual approach of single-station (non-ergodic) sigma provides the framework for this. However, most datasets are still significantly lacking in data where they are of most relevance for long return-period hazard (records in the upper tails of the ground-motion distribution from moderate earthquakes and large events recorded at near distances). The robustness of models describing this variability is, therefore, called into question. Improved approaches for modeling data with mixed sampling in the model space, obtaining additional empirical data, and the reliable simulation of such data is, therefore, of great importance.

In some senses, seismology is analogous to economics in that we cannot do full-scale controlled experiments, e.g. we cannot replay an earthquake (seismology) or a recession (economics) with slightly altered input parameters. Unlike economics, however, in seismology we generally do not have masses of data. Perhaps there are some statistical tools and approaches that are used in economics that could be applied to seismological data or models, 
e.g. in the assessment of epistemic uncertainty. Although as noted by, for example, Kahneman (2012) experts in economics and in other fields find it challenging to correctly assess what they know and, equally important, what they do not know. There is clearly a need in ground-motion prediction to improve the calibration of the level of epistemic uncertainty modeled by GMPEs within seismic hazard assessments.

Douglas et al. (2014b) find that often the more expensive, carefullyundertaken assessments for single sites model higher uncertainty than cheaper regional assessments, which is a demonstration of an inconsistency in capturing epistemic uncertainty. However, it should be noted that the primary objective of more elaborate assessments, such as those following the SSHAC guidelines (Budnitz et al., 1997), is to ensure the capture of epistemic uncertainty. The higher study levels in SSHAC increase the likelihood of this objective being met. Therefore, it should not surprise us that the uncertainty ranges from SSHAC Level 3 or 4 studies are greater than those in small studies performed more informally by an individual or a small team. On the other hand, epistemic uncertainty is reduced by data collection. In the Thyspunt PSHA (Bommer et al., 2015), for example, without the historical seismicity studies, geological investigations and extensive velocity measurements at the site, the total uncertainty in the final hazard assessments would have been considerably larger. More expensive studies are, therefore, forced to undertake more analyses to assure that epistemic uncertainty is reduced, as opposed to smaller studies that may simply make an assumption that the overall epistemic uncertainty is at a given level.

The growth of unconventional gas and oil extraction and associated fluid injection and, to a lesser extent, geothermal energy has led to a significant increase in induced seismicity (Rubinstein and Mahani, 2015). This fo- 
cus has seen several GMPEs being published for the purpose of predicting ground motion from small earthquakes at very short distances. While common wisdom would suggest that damage due to induced seismicity, which is generally limited to events with $M<5$, is negligible, there have been cases of significant insured losses (Giardini, 2009), although what proportion of damage is earthquake-related is debatable.

As noted above, some authors (Field et al., 2003; Atkinson, 2012) have argued that GMPEs will soon be replaced by numerical simulations of earthquake shaking. Such simulations do provide a much richer representation of the earthquake hazard to engineers (full time-histories rather than simply intensity measures) and they allow source- and site-specific calculations, although for a limited structural period range. For poorly-sampled magnitudedistance ranges and unusual source (e.g. deep crustal sources), path (e.g. strong velocity contrasts) and site conditions (e.g. nonlinear soils) simulations are invaluable in guiding the development of GMPEs. The general consensus is that full-waveform simulation approaches are currently not sufficiently constrained, however, to form the basis of hazard analyses due to their reliance on a full understanding of the physical system (including effects such as plastic deformation, fault shape and roughness). They are at a stage, however, where simulations provide valuable insight into the expected behavior of source effects and wave propagation in heterogeneous media, which can be combined with empirical data and analyses. Although ground-motion simulations show significant advances with the advent of high-performance computing and the development of better procedures, GMPEs are likely to remain a key component of hazard assessments for the foreseeable future.

One attractive approach to ground-motion simulation is "virtual earthquakes' (Denolle et al., 2014), in which the Green's functions measuring the 
Earth's response to point impulses are derived from the ambient seismic field (i.e. microtremors) and then these are used to predict ground motion from a series of point sources to model fault rupture. This approach captures the effect of travel path in the region, e.g. sedimentary basin effects, but it is currently restricted to structural periods longer than $3 \mathrm{~s}$. For long periods it may be possible to simulate ground motions using this technique for the derivation of ground-motion models but an outstanding issue is assessing the variability and uncertainty associated with these simulations.

Treverton (2007) discusses the difference between a puzzle and a mystery. To solve a puzzle you need more information while to solve a mystery requires clever analysis of the information that is already available. Groundmotion prediction currently is more of a puzzle, because data are limited, whilst it is often seen as a mystery, where complex analysis is applied to very little data. As noted by Atkinson (2004) for 'every dollar that is spent trying to quantify uncertainty, we should spend 10 dollars collecting and analyzing data that would reduce uncertainty'. While we have seen significant changes in many, if not most, recent PSHAs compared to earlier studies, due to the advancement of state-of-practice, a significant contribution to this can be put down to the availability of new data and better treatment of it in PSHA. Collection of more strong-motion data and, equally important, the associated metadata (e.g. local site conditions) is the only reliable way of reducing uncertainty in ground-motion prediction and hence it should be prioritized. With the rapid decrease in the cost of strong-motion instrumentation and the ease-of-use of new sensors, there is hope that the era of only recording a single near-source accelerogram from a M7.8 earthquake [as was the case for the Gorkha (Nepal) earthquake of 25th April 2015] is coming to an end. Strong-motion monitoring in seismic areas could be encouraged 
by, for example: providing instruments to schools for use as an educational tool, installing sensors in public buildings, and requiring instrumentation as part of the building code for infrastructure (e.g. power plants). Large earthquakes occur infrequently and they present an opportunity to significantly improve our knowledge of earthquake shaking, which is vital in the reduction of seismic risk.

Our understanding of earthquake hazard has improved dramatically in the past decades. Therefore, is it necessary to continue refining seismic hazard assessments when the results are unlikely to change dramatically? We argue that such refinement is required if not from a purely scientific point of view but because it is important from the regulator's viewpoint that all avenues are explored and the best analysis is performed. Many drug trials are conducted that demonstrate that a drug is not useful but it is not then argued that the trial was a waste of money - why should seismic hazard assessment be any different? The seismological community cannot be seen to be resting on our laurels and not striving for improved knowledge and understanding. In addition, while significant recent advances have been made in education, it is necessary to continue to train the next generation of engineering seismologists so that they can produce high-quality hazard assessments and, equally important, to understand what such assessments mean. Examples of this should focus on two important elements: a) handson experience in real projects (most training is typically theoretical and in the authors' experience is not completely aligned with real projects), and b) funding science and data collection underlying earthquake engineering and engineering seismology.

Finally, while significant advances have been made in ground-motion prediction over the past decade, we are continually surprised by unexpected 
events. Recent examples include the high PGAs recorded during the M9

Tohoku earthquake $(2.7 \mathrm{~g})$; the long-period (3-5 s) motions (over $4 \mathrm{~m} / \mathrm{s}$ ) recorded during the M7.8 Gorkha, Nepal event with recorded peak displacements of up to $1.87 \mathrm{~m}$; and in lower seismicity areas the Market Rasen (M4.5, UK) and St Die (M4.8, France) earthquakes (Ottemöller and Sargeant, 2010; Scherbaum et al., 2004), which exhibited much higher than expected motions than expected using local ground-motion models. It is clear, therefore, that while advances are welcome in aspects such as median predictions and the capture of uncertainty, we still lack full understanding of the fundamentals of source-, path- and site-specific earthquake ground motion.

\section{Acknowledgments}

Some of the ideas presented here were discussed during the Theme Lecture of Douglas (2014). We thank Julian Bommer and Fabrice Cotton for their careful reviews of an early version of this article, which led to significant improvements to the article.

\section{References}

Abrahamson, N., Atkinson, G., Boore, D., Bozorgnia, Y., Campbell, K., Chiou, B., Idriss, I. M., Silva, W., Youngs, R., Feb 2008. Comparisons of the NGA ground-motion relations. Earthquake Spectra 24 (1), 45-66.

Abrahamson, N. A., Silva, W. J., Kamai, R., Aug 2014. Summary of the ASK14 ground motion relation for active crustal regions. Earthquake Spectra 30 (3), 1025-1055. 
Abrahamson, N. A., Youngs, R. R., Feb 1992. A stable algorithm for regression analyses using the random effects model. Bulletin of the Seismological Society of America 82 (1), 505-510.

Akkar, S., Bommer, J. J., Mar/Apr 2010. Empirical equations for the prediction of PGA, PGV and spectral accelerations in Europe, the Mediterranean region and the Middle East. Seismological Research Letters 81 (2), 195-206.

Akkar, S., Çağnan, Z., Yenier, E., Erdoğan, O., Sandıkkaya, A., Gülkan, P., 2010. The recently compiled Turkish strong-motion database: Preliminary investigation for seismological parameters. Journal of Seismology 14 (3), $457-479$

Akkar, S., Sandıkkaya, M. A., Bommer, J. J., 2014a. Empirical groundmotion models for point- and extended-source crustal earthquake scenarios in Europe and the Middle East. Bulletin of Earthquake Engineering $12(1), 359-387$.

Akkar, S., Sandıkkaya, M. A., Şenyurt, M., Azari, A. S., Ay, B. O., Traversa, P., Douglas, J., Cotton, F., Luzi, L., Hernandez, B., Godey, S., 2014b. Reference database for seismic ground-motion in Europe (RESORCE). Bulletin of Earthquake Engineering 12 (1), 311-339.

Al Atik, L., 2015. NGA-East: Ground-motion standard deviation models for central and eastern North America. PEER Report 2015/07, Pacific Earthquake Engineering Research Center, University of California at Berkeley, USA.

Al Atik, L., Abrahamson, N., Bommer, J. J., Scherbaum, F., Cotton, F., 
Kuehn, N., Sep/Oct 2010. The variability of ground-motion prediction models and its components. Seismological Research Letters 81 (5), 794801.

Al Atik, L., Kottke, A., Abrahamson, N., Hollenback, J., 2013. Kappa ( scaling of ground-motion prediction equations using an inverse random vibration theory approach. Bulletin of the Seismological Society of America 104 (1), 336-346.

Al Atik, L., Youngs, R. R., Aug 2014. Epistemic uncertainty for NGA-West2 models. Earthquake Spectra 30 (3), 1301-1318.

Allmann, B. P., Shearer, P. M., 2007. Spatial and temporal stress drop variations in small earthquakes near Parkfield, California. Journal of Geophysical Research 112 (B04305).

Ambraseys, N. N., Bommer, J. J., 1991. The attenuation of ground accelerations in Europe. Earthquake Engineering and Structural Dynamics 20 (12), 1179-1202.

Ambraseys, N. N., Douglas, J., Sarma, S. K., Smit, P. M., 2005. Equations for the estimation of strong ground motions from shallow crustal earthquakes using data from Europe and the Middle East: Horizontal peak ground acceleration and spectral acceleration. Bulletin of Earthquake Engineering 3 (1), 1-53.

Ambraseys, N. N., Free, M. W., 1997. Surface-wave magnitude calibration for European region earthquakes. Journal of Earthquake Engineering $1(1), 1-22$. 
Ambraseys, N. N., Simpson, K. A., Bommer, J. J., 1996. Prediction of horizontal response spectra in Europe. Earthquake Engineering and Structural Dynamics 25 (4), 371-400.

Anderson, J. G., Brune, J. N., 1999. Probabilistic seismic hazard assessment without the ergodic assumption. Seismological Research Letters 70 (1), $19-28$

Anderson, J. G., Hough, S. E., Oct 1984. A model for the shape of the Fourier amplitude spectrum of acceleration at high frequencies. Bulletin of the Seismological Society of America 74 (5), 1969-1993.

Arias, A., 1970. A measure of earthquake intensity. In: Hansen, R. (Ed.), Seismic Design for Nuclear Power Plants. The M.I.T. Press, pp. 438-483.

ASCE, 2013. Minimum design loads for buildings and other structures. Tech. Rep. ASCE/SEI 7-10, Committee on Minimum Design Loads for Buildings and Other Structures of the Codes and Standards Activities Division of Structural Engineering Institute.

Atkinson, G. M., 2004. An overview of developments in seismic hazard analysis. In: Proceedings of Thirteenth World Conference on Earthquake Engineering. Paper no. 5001.

Atkinson, G. M., Apr 2006. Single-station sigma. Bulletin of the Seismological Society of America 96 (2), 446-455.

Atkinson, G. M., Apr 2010. Ground motion prediction equations for Hawaii from a referenced empirical approach. Bulletin of the Seismological Society of America 100 (2), 751-761. 
Atkinson, G. M., 2012. Integrating advances in ground-motion and seismichazard analysis. In: Proceedings of Fifteenth World Conference on Earthquake Engineering.

Atkinson, G. M., Apr 2015. Ground-motion prediction equation for smallto-moderate events at short hypocentral distances, with application to induced-seismicity hazards. Bulletin of the Seismological Society of America 105 (2A), 981-992.

Atkinson, G. M., Beresnev, I., Jan/Feb 1997. Don`t call it stress drop. Seismological Research Letters 68 (1), 3-4.

Atkinson, G. M., Bommer, J. J., Abrahamson, N. A., Oct 2014. Alternative approaches to modeling epistemic uncertainty in ground motions in probabilistic seismic-hazard analysis. Seismological Research Letters 85 (6), $1141-1144$.

Atkinson, G. M., Silva, W., Apr 2000. Stochastic modeling of California ground motion. Bulletin of the Seismological Society of America 90 (2), $255-274$.

Baker, J. W., 2011. Conditional mean spectrum: Tool for ground motion selection. Journal of Structural Engineering, ASCE 137 (3), 322-331.

Baker, J. W., Jayaram, N., 2008. Correlation of spectral acceleration values from NGA ground motion models. Earthquake Spectra 24 (1), 299-317.

Bakun, W. H., 1984. Seismic moments, local magnitudes, and coda-duration magnitudes for earthquakes in central California. Bulletin of the Seismological Society of America 74 (2), 439-458. 
Baltay, A. S., Hanks, T. C., Dec 2014. Understanding the magnitude dependence of PGA and PGV in NGA-West 2 data. Bulletin of the Seismological Society of America 104 (6), 2851-2865.

Bazzurro, P., Cornell, C. A., Apr 1999. Disaggregation of seismic hazard. Bulletin of the Seismological Society of America 89 (2), 501-520.

Beauval, C., Tasan, H., Laurandeau, A., Delavaud, E., Cotton, F., Guéguen, P., Kuehn, N., 2012. On the testing of ground-motion prediction equations against small-magnitude data. Bulletin of the Seismological Society of America 102 (5), 1994-2007.

Berge-Thierry, C., Cotton, F., Scotti, O., Griot-Pommera, D.-A., Fukushima, Y., 2003. New empirical response spectral attenuation laws for moderate European earthquakes. Journal of Earthquake Engineering 7 (2), 193-222.

Bindi, D., Massa, M., Luzi, L., Ameri, G., Pacor, F., Puglia, R., Augliera, P., 2014. Pan-European ground-motion prediction equations for the average horizontal component of PGA, PGV, and 5\%-damped PSA at spectral periods up to $3.0 \mathrm{~s}$ using the RESORCE dataset. Bulletin of Earthquake Engineering 12 (1), 391-430.

Bindi, D., Spallarossa, D., Eva, C., Cattaneo, M., 2005. Local and duration magnitudes in northwestern Italy, and seismic moment versus magnitude relationships. Bulletin of the Seismological Society of America 95 (2), 592604.

Bommer, J. J., Akkar, S., Feb 2012. Consistent source-to-site distance met- 
rics in ground-motion prediction equations and seismic source models for PSHA. Earthquake Spectra 28 (1), 1-15.

Bommer, J. J., Akkar, S., Drouet, S., 2012. Extending ground-motion prediction equations for spectral accelerations to higher response frequencies. Bulletin of Earthquake Engineering 10 (2), 379-399.

Bommer, J. J., Alarcón, J. E., 2006. The prediction and use of peak ground velocity. Journal of Earthquake Engineering 10 (1), 1-31.

Bommer, J. J., Coppersmith, K. J., Coppersmith, R. T., Hanson, K. L., Mangongolo, A., Neveling, J., Rathje, E. M., Rodriguez-Marek, A., Scherbaum, F., Shelembe, R., Stafford, P. J., Strasser, F. O., May 2015. A SSHAC level 3 probabilistic seismic hazard analysis for a new-build nuclear site in South Africa. Earthquake Spectra 31 (2), 661-698.

Bommer, J. J., Dost, B., Edwards, B., Stafford, P. J., van Elk, J., Doornhof, D., Ntinalexis, M., 2016. Developing an application-specific groundmotion model for induced seismicity. Bulletin of the Seismological Society of America 106 (1), 158-173.

Bommer, J. J., Douglas, J., Scherbaum, F., Cotton, F., Bungum, H., Fäh, D., 2010. On the selection of ground-motion prediction equations for seismic hazard analysis. Seismological Research Letters 81 (5), 783-793.

Bommer, J. J., Oates, S., Cepeda, J. M., Lindholm, C., Bird, J., Torres, R., Marroqun, G., Rivas, J., 2006. Control of hazard due to seismicity induced by a hot fractured rock geothermal project. Engineering Geology 83, 287-306. 
Bommer, J. J., Scherbaum, F., Bungum, H., Cotton, F., Sabetta, F., Abrahamson, N. A., Apr 2005. On the use of logic trees for ground-motion prediction equations in seismic-hazard analysis. Bulletin of the Seismological Society of America 95 (2), 377-389.

Bommer, J. J., Stafford, P. J., Alarcón, J. E., Akkar, S., 2007. The influence of magnitude range on empirical ground-motion prediction. Bulletin of the Seismological Society of America 97 (6), 2152-2170.

Boore, D. M., Mar 2003. Simulation of ground motion using the stochastic method. Pure and Applied Geophysics 160 (3-4), 635-676.

Boore, D. M., Dec 2009. Comparing stochastic point-source and finite-source ground-motion simulations: SMSIM and EXSIM. Bulletin of the Seismological Society of America 99 (6), 3202-3216.

Boore, D. M., Atkinson, G. M., 2008. Ground-motion prediction equations for the average horizontal component of PGA, PGV, and 5\%-damped PSA at spectral periods between $0.01 \mathrm{~s}$ and $10.0 \mathrm{~s}$. Earthquake Spectra 24 (1), 99-138.

Boore, D. M., Joyner, W. B., Fumal, T. E., 1993. Estimation of response spectra and peak accelerations from western North American earthquakes: An interim report. Open-File Report 93-509, U.S. Geological Survey, 70 pages.

Boore, D. M., Joyner, W. B., Fumal, T. E., Jan/Feb 1997. Equations for estimating horizontal response spectra and peak acceleration from western North American earthquakes: A summary of recent work. Seismological Research Letters 68 (1), 128-153. 
Boore, D. M., Stewart, J. P., Seyhan, E., Atkinson, G. M., 2013. NGAWest2 equations for predicting response spectral accelerations for shallow crustal earthquakes. Tech. Rep. 2013/05, Pacific Earthquake Engineering Research Center, College of Engineering, University of California, Berkeley.

Boore, D. M., Stewart, J. P., Seyhan, E., Atkinson, G. M., Aug 2014. NGAWest 2 equations for predicting PGA, PGV, and 5\%-damped PSA for shallow crustal earthquakes. Earthquake Spectra 30 (3), 1057-1085.

Boore, D. M., Thompson, E. M., Cadet, H., 2011. Regional correlations of $V_{S 30}$ and velocities averaged over depths less than and greater than 30 meters. Bulletin of the Seismological Society of America 101 (6), 30463059.

Boore, D. M., Watson-Lamprey, J., Abrahamson, N. A., Aug 2006. Orientation-independent measures of ground motion. Bulletin of the Seismological Society of America 96 (4A), 1502-1511.

Bora, S. S., Scherbaum, F., Kuehn, N., Stafford, P., Jun 2016. On the relationship between Fourier and response spectra: Implications for the adjustment of empirical ground-motion prediction equations (GMPEs). Bulletin of the Seismological Society of America 106 (3), 1235-1253.

Bora, S. S., Scherbaum, F., Kuehn, N., Stafford, P., Edwards, B., Aug 2015. Development of a response spectral ground-motion prediction equation (GMPE) for seismic-hazard analysis from empirical Fourier spectral and duration models. Bulletin of the Seismological Society of America 105 (4), 2192-2218. 
Bourne, S. J., Oates, S. J., Bommer, J. J., Dost, B., van Elk, J., Doornhof, D., Jun 2015. Monte Carlo method for probabilistic hazard assessment of induced seismicity due to conventional natural gas production. Bulletin of the Seismological Society of America 105 (3), 1721-1738.

Bozorgnia, Y., Abrahamson, N. A., Al Atik, L., Ancheta, T. D., Atkinson, G. M., Baker, J. W., Baltay, A., Boore, D. M., Campbell, K. W., Chiou, B. S.-J., Darragh, R., Day, S., Donahue, J., Graves, R. W., Gregor, N., Hanks, T., Idriss, I. M., Kamai, R., Kishida, T., Kottke, A., Mahin, S. A., Rezaeian, S., Rowshandel, B., Seyhan, E., Shahi, S., Shantz, T., Silva, W., Spudich, P., Stewart, J. P., Watson-Lamprey, J., Wooddell, K., Youngs, R., Aug 2014. NGA-West2 research project. Earthquake Spectra 30 (3), 973-987.

Bradley, B. A., 2011. Correlation of significant duration with amplitude and cumulative intensity measures and its use in ground motion selection. Journal of Earthquake Engineering 15 (6), 809-832.

Brady, A. G., Trifunac, M. D., Hudson, D. E., Feb 1973. Analyses of strong motion earthquake accelerograms - response spectra. Tech. rep., Earthquake Engineering Research Laboratory - California Institute of Technology.

Brune, J. N., Sep 1970. Tectonic stress and the spectra of seismic shear waves from earthquakes. Journal of Geophysical Research 75 (26), 4997-5009.

Budnitz, R. J., Apostolakis, G., Boore, D. M., Cluff, L. S., Coppersmith, K. J., Cornell, C. A., Morris, P. A., 1997. Recommendations for probabilistic seismic hazard analysis: Guidance on uncertainty and use of ex- 
perts. Tech. Rep. NUREG/CR-6372, US Nuclear Regulatory Commission, Washington D.C., two volumes.

Campbell, K. W., Aug 1985. Strong motion attenuation relations: A tenyear perspective. Earthquake Spectra 1 (4), 759-804.

Campbell, K. W., 2003. Prediction of strong ground motion using the hybrid empirical method and its use in the development of ground-motion (attenuation) relations in eastern North America. Bulletin of the Seismological Society of America 93 (3), 1012-1033.

Campbell, K. W., Bozorgnia, Y., 2008. NGA ground motion model for the geometric mean horizontal component of PGA, PGV, PGD and 5\% damped linear elastic response spectra for periods ranging from 0.01 to 10 s. Earthquake Spectra 24 (1), 139-171.

Campbell, K. W., Bozorgnia, Y., Aug 2014. NGA-West2 ground motion model for the average horizontal components of PGA, PGV, and 5\%damped linear acceleration response spectra. Earthquake Spectra 30 (3), $1087-1115$.

Cartwright, D. E., Longuet-Higgins, M. S., 1956. The statistical distribution of the maxima of a random function. Proceedings of the Royal Society of London Series A — Mathematical and Physical Sciences 237 (1209), 212232.

Castellaro, S., Mulargia, F., Rossi, P. L., 2008. Vs30: Proxy for seismic amplification? Seismological Research Letters 79 (4), 540-543.

Cauzzi, C., Faccioli, E., Oct 2008. Broadband (0.05 to $20 \mathrm{~s}$ ) prediction of 
displacement response spectra based on worldwide digital records. Journal of Seismology 12 (4), 453-475.

Cauzzi, C., Faccioli, E., Vanini, M., Bianchini, A., Jun 2015. Updated predictive equations for broadband (0.01-10s) horizontal response spectra and peak ground motions, based on a global dataset of digital acceleration records. Bulletin of Earthquake Engineering 13 (6), 1587-1612.

Chiou, B., Darragh, R., Gregor, N., Silva, W., Feb 2008. NGA project strong-motion database. Earthquake Spectra 24 (1), 23-44.

Chiou, B. S.-J., Youngs, R. R., 2008. An NGA model for the average horizontal component of peak ground motion and response spectra. Earthquake Spectra 24 (1), 173-215.

Chiou, B. S.-J., Youngs, R. R., Aug 2014. Update of the Chiou and Youngs NGA model for the average horizontal component of peak ground motion and response spectra. Earthquake Spectra 30 (3), 1117-1153.

Chopra, A. K., 1995. Dynamics of Structures — Theory and Application to Earthquake Engineering. Prentice Hall International, Inc.

Comité Européen de Normalisation, Sep 2005. Eurocode 8, Design of structures for earthquake resistance - Part 1: General rules, seismic actions and rules for buildings. European Standard NF EN 1998-1.

Cornell, C. A., Oct 1968. Engineering seismic risk analysis. Bulletin of the Seismological Society of America 58 (5), 1583-1606.

Cotton, F., Archuleta, R., Causse, M., 2013. What is sigma of the stress drop? Seismological Research Letters 84 (1), 42-48. 
Cotton, F., Pousse, G., Bonilla, F., Scherbaum, F., Oct 2008. On the discrepancy of recent European ground-motion observations and predictions from empirical models: Analysis of KiK-net accelerometric data and pointsources stochastic simulations. Bulletin of the Seismological Society of America 98 (5), 2244-2261.

Cousins, W. J., Zhao, J. X., Perrin, N. D., Dec 1999. A model for the attenuation of peak ground acceleration in New Zealand earthquakes based on seismograph and accelerograph data. Bulletin of the New Zealand Society for Earthquake Engineering 32 (4), 193-220.

Cua, G., Wald, D. J., Allen, T. I., Garcia, D., Worden, C. B., Gerstenberger, M., Lin, K., Marano, K., Oct 2010. "Best practices" for using macroseismic intensity and ground motion intensity conversion equations for hazard and loss models in GEM1. Tech. Rep. 2010-4, GEM Foundation, Pavia, Italy.

Delavaud, E., Cotton, F., Akkar, S., Scherbaum, F., Danciu, L., Beauval, C., Drouet, S., Douglas, J., Basili, R., Sandikkaya, M. A., Segou, M., Faccioli, E., Theodoulidis, N., 2012. Toward a ground-motion logic tree for probabilistic seismic hazard assessments in Europe. Journal of Seismology $16(3), 451-473$.

Denolle, M. A., Dunham, E. M., Prieto, G. A., Beroza, G. C., Jan 2014. Strong ground motion prediction using virtual earthquakes. Science 343 (6169), 399-403.

Derras, B., Cotton, F., Bard, P.-Y., 2014. Towards fully data driven groundmotion prediction models for Europe. Bulletin of Earthquake Engineering 12 (1), 495-516. 
Douglas, J., 2003a. Earthquake ground motion estimation using strongmotion records: A review of equations for the estimation of peak ground acceleration and response spectral ordinates. Earth-Science Reviews 61 (1-2), 43-104.

Douglas, J., Aug 2003b. A note on the use of strong-motion data from small magnitude earthquakes for empirical ground motion estimation. In: Skopje Earthquake 40 Years of European Earthquake Engineering (SE40EEE).

Douglas, J., 2010a. Assessing the epistemic uncertainty of ground-motion predictions. In: Proceedings of the Ninth U.S. National and 10th Canadian Conference on Earthquake Engineering: Reaching Beyond Borders. Paper no. 219.

Douglas, J., 2010b. Consistency of ground-motion predictions from the past four decades. Bulletin of Earthquake Engineering 8 (6), 1515-1526.

Douglas, J., 2012. Consistency of ground-motion predictions from the past four decades: Peak ground velocity and displacement, Arias intensity and relative significant duration. Bulletin of Earthquake Engineering 10 (5), $1339-1356$.

Douglas, J., Aug 2014. Fifty years of ground-motion models. In: Proceedings of Second European Conference on Earthquake Engineering and Seismology (a joint event of the 14th ECEE \& 31st General Assembly of the $\mathrm{ESC})$.

Douglas, J., 2016. Ground motion prediction equations 1964-2016. Website: http://www.gmpe.org.uk. Last accessed June 202016. 
Douglas, J., Akkar, S., Ameri, G., Bard, P.-Y., Bindi, D., Bommer, J. J., Bora, S. S., Cotton, F., Derras, B., Hermkes, M., Kuehn, N. M., Luzi, L., Massa, M., Pacor, F., Riggelsen, C., Sandikkaya, M. A., Scherbaum, F., Stafford, P. J., Traversa, P., 2014a. Comparisons among the five groundmotion models developed using RESORCE for the prediction of response spectral accelerations due to earthquakes in Europe and the Middle East. Bulletin of Earthquake Engineering 12 (1), 341-358.

Douglas, J., Aochi, H., 2008. A survey of techniques for predicting earthquake ground motions for engineering purposes. Surveys in Geophysics $29(3), 187-220$.

Douglas, J., Aochi, H., Suhadolc, P., Costa, G., 2007. The importance of crustal structure in explaining the observed uncertainties in ground motion estimation. Bulletin of Earthquake Engineering 5 (1), 17-26.

Douglas, J., Boore, D. M., 2011. High-frequency filtering of strong-motion records. Bulletin of Earthquake Engineering 9 (2), 395-409.

Douglas, J., Edwards, B., Convertito, V., Sharma, N., Tramelli, A., Kraaijpoel, D., Cabrera, B. M., Maercklin, N., Troise, C., Jun 2013. Predicting ground motion from induced earthquakes in geothermal areas. Bulletin of the Seismological Society of America 103 (3), 1875-1897.

Douglas, J., Halldórsson, H., 2010. On the use of aftershocks when deriving ground-motion prediction equations. In: Proceedings of the Ninth U.S. National and 10th Canadian Conference on Earthquake Engineering: Reaching Beyond Borders. Paper no. 220.

Douglas, J., Jousset, P., Jul/Aug 2011. Modeling the difference in ground- 
motion magnitude-scaling in small and large earthquakes. Seismological Research Letters 82 (4), 504-508.

Douglas, J., Seyedi, D. M., Ulrich, T., Modaressi, H., Foerster, E., Pitilakis, K., Pitilakis, D., Karatzetzou, A., Gazetas, G., Garini, E., Loli, M., Jan 2015. Evaluation of seismic hazard for the assessment of historical elements at risk: Description of input and selection of intensity measures. Bulletin of Earthquake Engineering 13 (1), 49-65.

Douglas, J., Suhadolc, P., Costa, G., 2004. On the incorporation of the effect of crustal structure into empirical strong ground motion estimation. Bulletin of Earthquake Engineering 2 (1), 75-99.

Douglas, J., Ulrich, T., Bertil, D., Rey, J., Sep/Oct 2014b. Comparison of the ranges of uncertainty captured in different seismic-hazard studies. Seismological Research Letters 85 (5), 977-985.

Draper, N. R., Smith, H., 1998. Applied Regression Analysis, 3rd Edition. John Wiley \& Sons.

Drouet, S., Cotton, F., Aug 2015. Regional stochastic GMPEs in lowseismicity areas: Scaling and aleatory variability analysis - Application to the French Alps. Bulletin of the Seismological Society of America 105 (4), 1883-1902.

Edwards, B., Cauzzi, C., Danciu, L., Faeh, D., 2016. Assessment, adjustment and weighting of ground motion prediction models for the 2015 Swiss Seismic Hazard Maps. Bulletin of the Seismological Society of America 106 (4), in press. 
Edwards, B., Douglas, J., 2014. Magnitude scaling of induced earthquakes. Geothermics 52, 132-139.

Edwards, B., Fäh, D., Giardini, D., May 2011. Attenuation of seismic shear wave energy in Switzerland. Geophysical Journal International 185 (2), 967-984.

Edwards, B., Ktenidou, O.-J., Cotton, F., Abrahamson, N., Van Houtte, C., Fäh, D., Sep 2015. Epistemic uncertainty and limitations of the $\kappa_{0}$ model for near-surface attenuation at hard rock sites. Geophysical Journal International 202 (3), 1627-1645.

Esteva, L., Rosenblueth, E., 1964. Espectros de temblores a distancias moderadas y grandes. Boletin Sociedad Mexicana de Ingenieria Sesmica 2, 1-18, in Spanish.

Field, E. H., Jordan, T. H., Cornell, C. A., 2003. OpenSHA: A developing community-modeling environment for seismic hazard analysis. Seismological Research Letters 74 (4), 406-419.

Fukushima, Y., 1996. Scaling relations for strong ground motion prediction models with $M^{2}$ terms. Bulletin of the Seismological Society of America $86(2), 329-336$.

Giardini, D., Dec 2009. Geothermal quake risks must be faced. Nature 462, $848-849$.

Goda, K., Hong, H. P., Feb 2008. Spatial correlation of peak ground motions and response spectra. Bulletin of the Seismological Society of America 98 (1), 354-365. 
Goertz-Allmann, B. P., Edwards, B., 2014. Constraints on crustal attenuation and three-dimensional spatial distribution of stress drop in Switzerland. Geophysical Journal International 196 (1), 493-509.

Goertz-Allmann, B. P., Edwards, B., Bethmann, F., Deichmann, N., Clinton, J., Fäh, D., Giardini, D., 2011. A new empirical magnitude scaling relation for Switzerland. Bulletin of the Seismological Society of America 101 (6), 3088-3095.

Gölke, M., Coblentz, D., 1996. Origins of the European regional stress field. Tectonophysics 266 (1-4), 11-24.

Graves, R. W., Pitarka, A., Oct 2010. Broadband ground-motion simulation using a hybrid approach. Bulletin of the Seismological Society of America 100 (5A), 2095-2123.

Gregor, N., Abrahamson, N. A., Atkinson, G. M., Boore, D. M., Bozorgnia, Y., Campbell, K. W., Chiou, B. S.-J., Idriss, I. M. ad Kamai, R., Seyhan, E., Silva, W., Stewart, J. P., Youngs, R., Aug 2014. Comparison of NGA-West2 GMPEs. Earthquake Spectra 30 (3), 1179-1197.
Hanford.gov,
November
2014.
Hanford
sitewide
prob-
seismic hazard
Available
at: http://www.hanford.gov/page.cfm/OfficialDocuments/HSPSHA. Last accessed June 2016.
Harp, E. L., Wilson, R. C., 1995. Shaking intensity thresholds for rock falls and slides: Evidence from 1987 Whittier Narrows and Superstition Hills earthquake strong-motion records. Bulletin of the Seismological Society of America 85 (6), 1739-1757. 
Hermkes, M., Kuehn, N. M., Riggelsen, C., 2014. Simulataneous quantification of epistemic and aleatory uncertainty in GMPEs using Gaussian process regression. Bulletin of Earthquake Engineering 12 (1), 449-466.

Hough, S. E., 2014. Shaking from injection-induced earthquakes in the central and eastern United States. Bulletin of the Seismological Society of America 104 (5), 2619-2626.

Idriss, I. M., Aug 2014. An NGA-West2 empirical model for estimating the horizontal spectral values generated by shallow crustal earthquakes. Earthquake Spectra 30 (3), 1155-1177.

Jayaram, N., Baker, J. W., Dec 2010. Considering spatial correlation in mixed-effects regression and the impact on ground-motion models. Bulletin of the Seismological Society of America 100 (6), 3295-3303.

Joyner, W. B., Boore, D. M., Dec 1981. Peak horizontal acceleration and velocity from strong-motion records including records from the $1979 \mathrm{Im}$ perial Valley, California, earthquake. Bulletin of the Seismological Society of America 71 (6), 2011-2038.

Joyner, W. B., Boore, D. M., Apr 1993. Methods for regression analysis of strong-motion data. Bulletin of the Seismological Society of America $83(2), 469-487$.

Kahneman, D., 2012. Thinking, Fast and Slow. Penguin, London, UK.

Kale, O., Akkar, S., Apr 2013. A new procedure for selecting and ranking ground-motion prediction equations (GMPEs): The Euclidean-distance based ranking (EDR) method. Bulletin of the Seismological Society of America 103 (2A), 1069-1084. 
Kamai, R., Abrahamson, N. A., Silva, W. J., Aug 2014. Nonlinear horizontal site amplification for constraining the NGA-West2 GMPEs. Earthquake Spectra 30 (3), 1223-1240.

Kotha, S. R., Bindi, D., Cotton, F., 2016a. Erratum to: Partially nonergodic region specific GMPE for Europe and Middle-East. Bulletin of Earthquake EngineeringIn press.

Kotha, S. R., Bindi, D., Cotton, F., Apr 2016b. Partially non-ergodic region specific GMPE for Europe and Middle-East. Bulletin of Earthquake Engineering 14 (4), 1245-1263.

Kulkarni, R. B., Youngs, R. R., Coppersmith, K. J., 1984. Assessment of confidence intervals for results of seismic hazard analysis. In: Proceedings of Eighth World Conference on Earthquake Engineering. Vol. 1. pp. 263270.

Laurendeau, A., Cotton, F., Ktenidou, O.-J., Bonilla, L.-F., Hollender, F., Dec 2013. Rock and stiff-soil site amplification: Dependency on $V_{S 30}$ and kappa $\left(\kappa_{0}\right)$. Bulletin of the Seismological Society of America $103(6), 3131-$ 3148.

Lin, P.-S., Chiou, B., Abrahamson, N., Walling, M., Lee, C.-T., Cheng, C.T., Oct 2011. Repeatable source, site, and path effects on the standard deviation for empirical ground-motion prediction models. Bulletin of the Seismological Society of America 101 (5), 2281-2295.

Manighetti, I., Campillo, M., Bouley, S., Cotton, F., 2007. Earthquake scaling, fault segmentation, and structural maturity. Earth and Planetary Science Letters 253 (3), 429-438. 
McGarr, A., Fletcher, J. B., Feb 2005. Development of ground-motion prediction equations relevant to shallow mining-induced seismicity in the Trail Mountain area, Emery County, Utah. Bulletin of the Seismological Society of America 95 (1), 31-47.

McGuire, R. K., 1976. FORTRAN computer program for seismic risk analysis. Open-File Report 76-67, United States Department of the Interior Geological Survey.

Molkenthin, C., Scherbaum, F., Griewank, A., Kuehn, N., Stafford, P., Oct 2014. A study of the sensitivity of response spectral amplitudes on seismological parameters using algorithmic differentiation. Bulletin of the Seismological Society of America 104 (5), 2240-2252.

Musson, R. M. W., Mar 2009. Ground motion and probabilistic hazard. Bulletin of Earthquake Engineering 7 (3), 575-589.

National Earthquake Hazard Reduction Program, 1994. Recommended Provisions for Seismic Regulations for New Buildings. FEMA 222A.

Newmark, N. M., Hall, W. J., 1982. Earthquake Spectra and Design. Earthquake Engineering Research Institute, Berkeley, USA.

NIST, Nov 2011. Selecting and scaling earthquake ground motions for performing response-history analyses. Tech. Rep. NIST GCR 11-917-15, National Institute of Standards and Technology.

Ottemöller, L., Sargeant, S., 2010. Ground-motion difference between two moderate-size intraplate earthquakes in the United Kingdom. Bulletin of the Seismological Society of America 100 (4), 1823-1829. 
Pacific Earthquake Engineering Research Center, Apr 2015. NGA-East: Median ground-motion models for the central and eastern North America region. Tech. Rep. 2015/04, PEER, University of California, Berkeley, USA.

Papaspiliou, M., Kontoe, S., Bommer, J. J., Nov 2012. An exploration of incorporating site response into PSHA - Part I: Issues related to site response analysis methods. Soil Dynamics and Earthquake Engineering $42,302-315$.

Poggi, V., Edwards, B., Fäh, D., Feb 2011. Derivation of a reference shearwave velocity model from empirical site amplification. Bulletin of the Seismological Society of America 101 (1), 258-274.

Power, M., Chiou, B., Abrahamson, N., Bozorgnia, Y., Shantz, T., Roblee, C., Feb 2008. An overview of the NGA project. Earthquake Spectra 24 (1), $3-21$.

Radiguet, M., Cotton, F., Manighetti, I., Campillo, M., Douglas, J., 2009. Dependency of near-field ground motions on the structural maturity of the ruptured faults. Bulletin of the Seismological Society of America 99 (4), $2572-2581$.

Rietbrock, A., Strasser, F., Edwards, B., Feb 2013. A stochastic earthquake ground-motion prediction model for the United Kingdom. Bulletin of the Seismological Society of America 103 (1), 57-77.

Rodriguez-Marek, A., Cotton, F., Abrahamson, N. A., Akkar, S., Al Atik, L., Edwards, B., Montalva, G. A., Dawood, H. M., Nov 2013. A model for 
single-station standard deviation using data from various tectonic regions. Bulletin of the Seismological Society of America 103 (6), 3149-3163.

Rodriguez-Marek, A., Montalva, G. A., Cotton, F., Bonilla, F., Jun 2011. Analysis of single-station standard deviation using the KiK-net data. Bulletin of the Seismological Society of America 101 (3), 1242-1258.

Rodriguez-Marek, A., Rathje, E. M., Bommer, J. J., Scherbaum, F., Stafford, P. J., 2014. Application of single-station sigma and site response characterization in a probabilistic seismic hazard analysis for a new nuclear site. Bulletin of the Seismological Society of America 104 (4), 16011619.

Rubinstein, J. L., Mahani, A. B., Jul/Aug 2015. Myths and facts on wastewater injection, hydraulic fracturing, enhanced oil recovery, and induced seismicity. Seismological Research Letters 86 (4), 1060-1067.

Sandikkaya, M. A., Akkar, S., Bard, P.-Y., 2013. A nonlinear site amplifcation model for the new pan-European ground-motion prediction equations. Bulletin of the Seismological Society of America 103 (1), 19-32.

Scasserra, G., Stewart, J. P., Bazzurro, P., Lanzo, G., Mollaioli, F., 2009. A comparison of NGA ground-motion prediction equations to Italian data. Bulletin of the Seismological Society of America 99 (5), 2961-2978.

Scherbaum, F., Cotton, F., Smit, P., Dec 2004. On the use of response spectral-reference data for the selection and ranking of ground-motion models for seismic-hazard analysis in regions of moderate seismicity: The case of rock motion. Bulletin of the Seismological Society of America 94 (6), 2164-2185. 
Scherbaum, F., Delavaud, E., Riggelsen, C., 2009. Model selection in seismic hazard analysis: An information-theoretic perspective. Bulletin of the Seismological Society of America 99 (6), 3234-3247.

Scherbaum, F., Kuehn, N. M., Ohrnberger, M., Koehler, A., Nov 2010. Exploring the proximity of ground-motion models using high-dimensional visualization techniques. Earthquake Spectra 26 (4), 1117-1138.

Seyhan, E., Stewart, J. P., Aug 2014. Semi-empirical nonlinear site amplification from NGA-West 2 data and simulations. Earthquake Spectra $30(3), 1241-1256$.

Somerville, P. G., 2003. Magnitude scaling of the near fault rupture directivity pulse. Physics of the Earth and Planetary Interiors 137, 201-212.

Spudich, P., Rowshandel, B., Shahi, S. K., Baker, J. W., Chiou, B. S. J., 2014. Comparison of NGA-West2 directivity models. Earthquake Spectra 30 (3), 1199-1221.

Stafford, P. J., 2014. Crossed and nested mixed-effects approaches for enhanced model development and removal of the ergodic assumption in empirical ground-motion models. Bulletin of the Seismological Society of America 104 (2), 702-719.

Stafford, P. J., Strasser, F. O., Bommer, J. J., 2008. An evaluation of the applicability of the NGA models to ground-motion prediction in the EuroMediterranean region. Bulletin of Earthquake Engineering 6 (2), 149-177.

Stewart, J. P., Douglas, J., Javanbarg, M., Abrahamson, N. A., Bozorgnia, Y., Boore, D. M., Campbell, K. W., Delavaud, E., Erdik, M., Stafford, 
P. J., 2015. Selection of ground motion prediction equations for the Global Earthquake Model. Earthquake Spectra 31 (1), 19-45.

Strasser, F. O., Abrahamson, N. A., Bommer, J. J., Jan/Feb 2009. Sigma: Issues, insights, and challenges. Seismological Research Letters 80 (1), $40-56$.

Treverton, G. F., Jun 2007. Risks and riddles. Smithsonian Magazine 38 (3), 98-102.

Trifunac, M. D., Brady, A. G., Jun 1975. A study on the duration of strong earthquake ground motion. Bulletin of the Seismological Society of America $65(3), 581-626$.

Vamvatsikos, D., Cornell, C. A., 2002. Incremental dynamic analysis. Earthquake Engineering and Structural Dynamics 31, 491-514.

Vanmarcke, E. H., Gasparini, D. A., 1976. Simulated earthquake motions compatible with prescribed response spectra. Tech. Rep. R76-4, Dept. of Civil Engineering, Massachusetts Inst. of Technology, Cambridge, USA.

Walling, M. A., Abrahamson, N. A., 2012. Non-ergodic probabilistic seismic hazard analyses. In: Proceedings of Fifteenth World Conference on Earthquake Engineering. Lisbon, Portugal, paper no. 1627.

Weatherill, G. A., Silva, V., Crowley, H., Bazzurro, P., 2015. Exploring the impact of spatial correlations and uncertainties for portfolio analysis in probabilistic seismic loss estimation. Bulletin of Earthquake Engineering $13(3), 957-981$.

Youngs, R. R., Abrahamson, N., Makdisi, F. I., Sadigh, K., Aug 1995. 
${ }_{1687}$ Magnitude-dependent variance of peak ground acceleration. Bulletin of 1688 the Seismological Society of America 85 (4), 1161-1176.

1689 Zhao, J. X., Zhang, J., Asano, A., Ohno, Y., Oouchi, T., Takahashi, T., 1690 Ogawa, H., Irikura, K., Thio, H. K., Somerville, P. G., Fukushima, Y., 1691 Fukushima, Y., 2006. Attenuation relations of strong ground motion in 1692 Japan using site classification based on predominant period. Bulletin of 1693 the Seismological Society of America 96 (3), 898-913. 